\title{
Numerical investigation of web crippling in fastened aluminium lipped channel sections under two-flange loading conditions
}

\author{
Husam Alsanat \\ School of Engineering and Built Environment, Griffith University \\ Gold Coast campus, QLD, 4222, Australia \\ School of Engineering, Al-Hussein Bin Talal University, Ma'an, Jordan \\ Shanmuganathan Gunalan \\ School of Engineering and Built Environment, Griffith University \\ Gold Coast campus, QLD, 4222, Australia \\ Keerthan Poologanathan \\ Faculty of Engineering and Environment, University of Northumbria, \\ Newcastle, UK \\ Hong Guan \\ School of Engineering and Built Environment, Griffith University \\ Gold Coast campus, QLD, 4222, Australia \\ Konstantinos Daniel Tsavdaridis \\ School of Civil Engineering, University of Leeds, LS2 9JT, Leeds, UK
}

\begin{abstract}
Aluminium alloys have recently been utilised in the fabrication of thin-walled members using a roll-forming technique to produce purlins, floor joists and other structural bearers. Such members are often subjected to transversely concentrated loads which may possibly cause a critical web crippling failure. Aluminium specifications do not explicitly provide clear design guidelines for roll-formed members subjected to web crippling actions. Therefore, this study was conducted to investigate the mechanism of web crippling for roll-formed aluminium lipped channel (ALC) sections with flanges attached to supports (fastened) under two-flange loading conditions. Based on the experimental works presented in a companion paper, numerical simulations were conducted including an extensive parametric study covering a wide range of ALC geometrical dimensions, bearing lengths, and 5052 aluminium alloy grade with H32, H36 and $\mathrm{H} 38$ tempers. The acquired web crippling data were then used to investigate the influence of the flange restraints on the web crippling mechanism of the ALC sections. Furthermore, a detailed assessment of the consistency and reliability of the currently available design rules used in practice was carried out. The predictions of the web crippling design guidelines given in the Australian, American and European specifications were found to be unsafe and
\end{abstract}


unreliable, whereas a good agreement was obtained between the predictions of our recently proposed design guidelines and acquired web crippling results. Further a suitable Direct Strength Method (DSM)-based design approach was developed in this study with associated equations to predict the elastic bucking and plastic loads of fastened ALC sections under twoflange loading conditions.

Keywords: Web crippling; Aluminium lipped channel sections; Two-flange loading conditions; Fastened; Numerical simulations; Design guidelines.

\section{Introduction}

Structural applications of aluminium alloys have recently increased in building construction industry. The inherent characteristics of aluminium alloys including light-weight, corrosion resistance, and ease of fabrication and shaping have attracted designers' attention in a wide range of building applications especially those in harsh industrial and marine environments [1]. Thin-walled members fabricated by aluminium alloys have recently been employed in the construction and building industries as purlins, floor joists and other structural bearers, and therefore are potentially susceptible to various types of instabilities similar to thin-walled steel members. Such structural members are highly prone to concentrated loads applied transversely, which may lead to localised failure to the web called web crippling.

In real-life scenarios, aluminium structural members supported by column, bearers or rafters and highly loaded by joists, purlins or live loading may induce web crippling failure. Depends on the locations of the load and support, four failure scenarios can be potentially occurred according to the AISI Standard test method [2]. If the loading and support are in the same line of action, the member fails under two-flange loading conditions (end-two-flange (ETF) and interior-two-flange (ITF)), otherwise one-flange loading conditions (end-one-flange (EOF) and interior-one-flange (IOF)) are experienced. These loading conditions are further classified in terms of the flange restraints, such as unfastened and fastened. It is worth to mention that the majority of the available studies, both experimental and numerical ones, were conducted on unfastened members [3-13] while limited studies [14-20] have been undertaken on fastened sections even though the latter is often found in common real-life practice.

Several finite element analysis methods were utilised in the past to simulate thin-walled members under web crippling action. For fastened channel sections, Macdonald et al. [16] performed non-linear finite element analysis on unfastened/fastened cold formed steel lipped channel sections using ANSYS software. Recently, Janarthanan et al. [18] thoroughly 
investigated the use of quasi-static analysis based on the explicit integration scheme in ABAQUS. Fastened unlipped cold-formed steel channel sections were simulated under oneflange loading conditions. Unlike static general non-linear analysis and quasi-static analysis with implicit integration, Janarthanan et al. [18] found that explicit dynamic method have the ability to overcome certain convergence issues that former mentioned methods often encounter.

Investigating web crippling for aluminium members has also gained increasing attention in the last decade. Extruded aluminium sections under the web crippling action were mainly investigated [21-27] while limited studies were performed on roll-formed sections [28-30]. Zhou and Young [23] conducted web crippling experimental and numerical investigations on extruded square and rectangular hollow sections under the ETF and ITF loading conditions. The sections were fabricated using 6061-T6 and 6063-T5 heat-treated aluminium alloys. Nonlinear static analysis were employed for the simulations and the developed finite element models were verified against the experiments. Chen et al. [26] further investigated the web crippling behaviour and capacity of extruded square hollow sections by caring out experiments and numerical analyses. The influence of different boundary conditions, bearing lengths, web slenderness and loading conditions on the ultimate capacity and the section ductility were examined. Improved design rules were also developed based on a parametric study to estimate the web crippling capacity of the sections under four loading conditions. Recently, Zhou and Young [22] reported web crippling experimental and numerical studies of unfastened extruded aluminium alloy (6063-T5 and 6061-T6) unlipped and lipped channel sections. The finite element models were developed and analysed using nonlinear static analysis, and then used for an extensive parametric study.

Alsanat et al. [28, 29] experimentally and numerically studied the web crippling failure of unfastened ALC sections under two-flange loading conditions (ETF and ITF). A detailed assessment of the AS/NZS 1664.1 [31], AS/NZS 4600 [32] and Eurocode 3 [33] specifications was performed and suitable modifications were made to improve their accuracy and reliability. Alsanat et al. [30] also experimentally investigated the web crippling capacity of the ALC sections with flanges attached to the supports under both the ETF and ITF loading conditions, and a new prediction approach was developed to estimate the increase in the web crippling capacity due to the flange being restrained. It should be noted that extruded and roll-formed aluminium sections behave differently under buckling instabilities. This is due to the nature of manufacturing process as extruded members are fabricated with sharp corners while roll- 
formed sections are produced with rounded corners. Therefore, roll-formed sections under web crippling actions are generally exposed to eccentric loading which will significantly influence the behaviour and capacity of the members.

Owing to the empirical nature of the current methods for predicting the web crippling capacity, and the lack of numerical studies on fastened aluminium sections, this study was conducted to numerically investigate the web crippling phenomenon of fastened ALC sections under twoflange loading conditions and further investigate the influence of a wider range of parameters on the web crippling behaviour and capacity of fastened ALC sections. Accurate and reliable numerical models, using quasi-static analysis with explicit integration scheme in ABAQUS/CAE, were firstly developed and then validated against the experimental results [30] in terms of ultimate web crippling strength, load-vertical displacement response and failure mode. Based on the validation, an extensive parametric study comprising a various geometrical dimensions, bearing lengths, and aluminium alloy grades was carried out. The acquired web crippling database, in conjunction with that reported in Alsanat et al. [29] for unfastened ALC sections, were subsequently used to further explore the effect of restrained flanges on the main parameters associated with web crippling. Moreover, a detailed assessment for the currently available design rules was performed, and a DSM-based approach was developed in this study to determine the web crippling capacity of fastened ALC sections under two-flange loading conditions.

\section{Brief overview of experimental study}

Two series of web crippling tests, including 38 test specimens of the ALC sections with restrained flanges under the ETF and ITF loading conditions, were previously conducted by Alsanat et al. [30]. Aluminium alloy grade 5052-H36 was used in the fabrication of the specimens. Figures 1 (a) and (b) show the test set-up of fastened ALC sections under the ETF and ITF loading conditions, respectively, and Figure 1 (c) shows the section profile of a typical ALC section. Five different sectional sizes were considered and loaded by high strength bearing plate (bearing length $(N)$ ranged from $25 \mathrm{~mm}$ to $150 \mathrm{~mm}$ ). The specimens were cut to a specific length $(L)$ according to AISI S909 [2] $(L=3 h$ and $L=5 h$ for ETF and ITF loading conditions, respectively). Tables 1 and 2 summarise the dimensional details and the ultimate capacities of the fastened ALC sections under the ETF and ITF loading conditions, respectively. The top and bottom flanges of the specimen were attached to the bearing plates using M12 bolt per flange. Note that the label "ETF-20025-N100" indicates that the loading 
condition is ETF, the section height $(d)$ is $200 \mathrm{~mm}$, the thickness of the web $(t)$ is $2.5 \mathrm{~mm}$, and the length of the bearing plate $(N)$ is $100 \mathrm{~mm}$.

\section{Finite element study}

The finite element (FE) model of fastened ALC specimens under web crippling actions is described in this section in detail. The general purpose finite element program, ABAQUS Version 6.14 [34] was employed for this task due to its exceptional capabilities in simulating various structural elements under diverse loading scenarios. Quasi-static analysis with explicit integration was performed to simulate the slow movement of the loading plate during the experimental tests. It has been proven that such analysis has the ability to overcome certain contact and convergence difficulties that implicit (static) integrator often encounters [35]. Note that initial geometrical imperfections were not considered in the modelling process, as the applied load generated from the contact between the load bearing plate and corner radius has a large eccentricity with respect to the web portion. Natário, et al. [35] and Sundararajah et al. [6] verified this by investigating the influence of several possible geometrical imperfections for cold-formed steel lipped channel sections and found that their influence on the web crippling capacity is less than $1 \%$.

\subsection{Finite element type and mesh control}

The ALC sections were modelled using the general purpose S4R shell element, which is a linear 4 node deformable element with reduced integration, allowing for finite strains and changes in thickness. It has been proven that such type of element is suitable to simulate 3D thin-walled members under web crippling actions [6, 35]. The loading and support bearing plates were modelled using R3D4 discrete rigid elements since they are much stiffer compared to the section itself.

To achieve a high accuracy of the finite element solution and minimise the computational time of the analysis, the mesh size for numerical model were carefully selected. The details for mesh size sensitivity analysis were reported by Alsanat et al. [29] for unfastened aluminium lipped channel sections. Similar mesh size control is employed in this study. The lipped channel section was modelled using mesh size of $5 \times 5 \mathrm{~mm}$, except the corners as the finer mesh of $5 \times 1$ $\mathrm{mm}$ was assigned to ensure appropriate transformation of the internal stress throughout the web-flange junction. 


\subsection{Material properties}

The material properties employed in the numerical analysis were gained from conducting tensile coupon tests [30]. Fifteen coupons were extracted from the flat portion of the web of the sections and tested. Table 3 gives the mechanical properties including elastic modulus $(\mathrm{E})$, static $0.2 \%$ tensile proof stress $\left(\sigma_{0.2}\right)$ and ultimate tensile strength $\left(\sigma_{u}\right)$ and strain $(\varepsilon u)$. The engineering stress-strain curves obtained from coupon tests were converted to the true stressstrain curves using Equations (1) and (2), since web crippling problems may involve high plastic strains.

$$
\begin{aligned}
& \sigma_{\text {true }}=\sigma_{\text {eng }}\left(1+\varepsilon_{\text {eng }}\right) \\
& \varepsilon_{\text {true }}=\ln \left(1+\varepsilon_{\text {eng }}\right)
\end{aligned}
$$

where $\sigma_{\text {true }}$ is the true stress $(\mathrm{MPa}), \varepsilon_{\text {true }}$ is the true strain, $\sigma_{\text {eng }}$ is the engineering stress ( $\left.\mathrm{MPa}\right)$ and $\varepsilon_{\text {eng }}$ is the engineering strain.

Figure 2 shows the typical engineering and true stress-strain curves for the 5052 H36 aluminium alloy. The material model consists of two parts; the elastic modulus of the material was identified to represent the elastic region while the plastic region was considered using the true plastic stress-strain curve. Despite the fact that the material properties for the corners differ from the web portion, the acquired material properties were used to model the whole section including the corners. It is believed that the changes in the material properties for the corners will not affect the ultimate web crippling capacity and behaviour for models failed in pure web crippling. Also, the models experienced flange crushing were not considered in proposing design rules.

\subsection{Contact and constraint definition}

The interactions between the bearing plate, the ALC sections and the bolts were modelled precisely using Contact Pair and Multi-Point Constraint (MPC) algorithms in ABAQUS [34]. The Contact Pair algorithm with a Penalty contact method was employed to simulate contact between deformable bodies (lipped channel section) and rigid elements (bearing plates). The contact formulation was assumed to be "Hard", and a friction coefficient of 0.4 was assigned to avoid any frictional slip. To simulate the bolt connection, Multi-Point Constraint (MPC) with rigid ties were identified between the rigid plate and the bolt hole perimeter (Figure 3). Such constraint can prevent any rotational movement of the flange during the analyses so that the fastened condition can be adequately represented. 


\subsection{Boundary conditions and loading}

The boundary conditions were precisely assigned to the models to simulate the actual experimental scenario. Reference Points were used to assign the boundary conditions for the loading and support plates. Identical boundary conditions were assigned to both ETF and ITF models. As shown in Figure 3, the $U_{x}, U_{y}$ and $U_{z}$ translational movements, and $R_{y}$ and $R_{z}$ rotations were fully restrained at the support plate. The loading plate was restricted from $U_{x}$ and $U_{z}$ translational movement and $R_{y}$ and $R_{z}$ rotations, however the vertical downward movement $\left(U_{y}\right)$ was permitted.

In the analysis, both Smooth Step and Mass Scaling options were implemented to reduce any converge issues and accelerate the calculations. The Smooth Step Amplitude allowed the model to deform smoothly in the initial stage of the analysis by reducing the displacement while Mass Scaling options increased the mas density of the modelled elements which led to a significant reduction of the number of time increment generated from the quasi-static analysis [34].

Simulating the actual experimental loading rate $(2 \mathrm{~mm} / \mathrm{min})$ using Quasi-static analysis with explicit integration is, in fact, highly time-consuming process (Natário et al. [34]). Therefore, both artificial loading rates and Mass Scaling methods are often implemented to accelerate the calculations. However, these methods may lead to a significant increase in the influence of the inertial effects and noise on the results. Therefore, the loading rate and mass scaling values were carefully assigned, and the kinetic-to-internal energy ratios were closely monitored. In this study, the loading rate of $25 \mathrm{~mm} / \mathrm{s}$ (total applied displacement $=25 \mathrm{~mm}$ and total step time $=1 \mathrm{~s}$ ) with smooth step amplitude (ramp procedure), and a constant Mass Scaling factor of 100 was assigned in the analysis. Default values of linear bulk viscosity parameters (damping coefficient value of 0.06) and quadratic bulk viscosity parameter (1.2) were assigned. Apart from the very first instants of the simulations, the kinetic-to-internal energy ratios remained below 5\% during the analysis.

\subsection{FEA Validation}

The developed 38 numerical models were compared with the experiments in terms of the ultimate capacity, load-vertical deformation responses and failure modes. The numerical web crippling results $\left(P_{F E A}\right)$ agreed very well with the experimental capacities $\left(P_{E x p}\right)$ for both the ETF and ITF loading conditions as shown in Tables 1 and 2, respectively. The mean and COV values of the $P_{E x p} / P_{F E A}$ ratios are 0.96 and 0.05 for the ETF loading condition, respectively, whereas these values are 0.99 and 0.05 , respectively, for the ITF loading condition. 
The load-vertical displacement responses and the failure modes obtained from the numerical simulations were also validated with the experiments. The load-vertical displacement responses of the numerical models were predicted including the post-failure stage, as presented in Figures 4 (a) and (b) for the loading conditions of ETF and ITF, respectively. Even though both comparisons show a strong agreement in the post-failure stages, the elastic stiffness observed in the initial stage noticeably differ for both loading conditions. It is believed that the measured vertical displacement was inevitably affected by the test rig settlement during the tests. Such a difference was also observed by Sundararajan et al. [6]. The failure modes of ETF25025-N100 and ITF-10030-N100 specimens as observed in the experiments and numerical analysis are compared in Figures 5 (a) and (b). In General, the numerical models are able to simulate the experimental tests of fastened ALC sections under two-flange loading conditions.

It was observed from the experimental and numerical investigations that specimens under ITF loading condition with $25 \mathrm{~mm}$ bearing plates experienced flange crushing failure. The numerical load-vertical displacement responses were validated with the experimental responses as shown in Figures 4 (c) for the ITF-20030-N25 specimen. Both the experimental and the numerical responses exhibited the flange crushing behaviour. Figure 5 (c) shows the agreement between the experimental and numerical failure modes of the ITF-25025-N25 specimen.

\subsection{Parametric study}

Based on the validated numerical models discussed in the previous section, a parametric study was conducted to explore the influence of various parameters on the web crippling capacity of fastened ALC sections under two-flange loading conditions. The acquired results obtained from both experiments and parametric analyses will then be used to assess the suitability of the design rules given in the current standards and Alsanat et al. [30]. New predictive Direct Strength Method (DSM) approach will also be developed based on these results.

The parametric study details are summarised in Table 4 as follow: $50 \mathrm{~mm} \leq N \leq 150 \mathrm{~mm}, 28$ $\leq h / t \leq 130$ and $2 \mathrm{~mm} \leq r_{i} \leq 8 \mathrm{~mm}$. Additionally, aluminium alloy grade 5052 with hardening of H32, H36 and H38 [31] were also considered. The length of specimens used in the parametric study was $3 d$ and $6 d$ for the ETF and ITF loading conditions as recommended by Alsanat et al. [29].

To consider the stain hardening effect, the bi-linear model proposed by Su et al. [36] for aluminium material was implemented in the parametric analyses as shown in Figure 2. The 
strain hardening slope $\left(E_{s h}\right)$ and the ultimate strain $\left(\varepsilon_{u}\right)$ can be calculate using Equations (3) and (4), respectively.

$$
\begin{gathered}
E_{s h}=\frac{f_{u}-f_{y}}{C_{2} \varepsilon_{u}-\varepsilon_{y}} \\
\varepsilon_{u}=C_{3}\left(1-\frac{f_{y}}{f_{u}}\right)+C_{4}
\end{gathered}
$$

where $C_{2}=0.5, C_{3}=0.13$, and $C_{4}=0.059$ are constants for aluminium material, $f_{y}$ is the yield stress, $f_{u}$ is the material ultimate stress $(\mathrm{MPa})$ and $\varepsilon_{y}$ is the yield strain.

\section{The effect of fastened flanges}

The acquired parametric results for fastened ALC sections and the parametric data reported by Alsanat et al.'s [29] for unfastened sections were analysed to explore the influence of fastened flanges on the section ultimate web crippling capacity. Typically, fastening the flanges has a substantial effect on the capacity of the ALC sections. Such restraint prevents flange rotation and consequently results in a significant reduction in the out-of-plane moment imposed on the web from the eccentric load. Hence, the overall capacity of the section will substantially increase. This can be confirmed by Figures 6 (a) and (b) which display the difference between unfastened and fastened specimens, respectively, in terms of failure modes.

Figure 7 compares the web crippling capacities of unfastened and fastened sections under the ETF and ITF loading conditions. Generally, flange restraining has more influence on the ETF sections, up to $88 \%$ increased strength with an average of $59 \%$, whereas, the ITF sections can gain up to $45 \%$ more capacity with an average of $22 \%$.

Figures 8 and 9 illustrate the influences of the major geometrical parameters $N / t$ and $h / t$, respectively on the web crippling capacity ratios $\left(P_{F} / P_{U}\right)$ of the ALC sections. Figure 8 shows the $P_{F} / P_{U}$ ratio versus the bearing length ratio $(N / t)$ for three different inside bent radii $\left(r_{i}\right)$ under both the ETF and ITF loading conditions. It can be seen that increasing the bearing length ratio $(N / t)$ results in a considerable increase to the capacity ratio $\left(P_{F} / P_{U}\right)$ of ALC sections. The $P_{F} / P_{U}$ ratios for the ETF specimens are more sensitive to such influence than the ITF specimens. It is also shown that varying the inside bend radii $\left(r_{i}\right)$ for the same $N / t$ has a minimal influence on the $P_{F} / P_{U}$ ratio. Figure 9 demonstrates the effects of the web slenderness ratios $(h / t)$ on $P_{F} / P_{U}$ ratios for three bearing lengths $(\mathrm{N})$ under the ETF and ITF loading conditions. As $h / t$ ratio increases, a relatively small increase in the $P_{F} / P_{U}$ ratios was observed compared to the influence of $N / t$ ratios. The ETF specimens loaded with the small bearing plates $(N=50 \mathrm{~mm})$ 
are more sensitive to the change in the $h / t$ ratio compared to the large bearing plates $(N=$ $100 \mathrm{~mm}$ and $150 \mathrm{~mm}$ ), whereas the ITF specimens behave similarly regardless of the change in the bearing length.

The relationship between the web crippling capacity ratio $\left(P_{F} / P_{U}\right)$ of the ALC sections and the geometrical factor $N h / t^{2}$ was investigated based on the experimental data reported by Alsanat et al $[28,30]$ covering both unfastened and fastened specimens. Increasing the $N h / t^{2}$ factor leads to a nonlinear increase the $P_{F} / P_{U}$ and novel predictive approach (fastening factor $\left(k_{f}\right)$ ) was proposed in Alsanat et al [30] to estimate the increased capacity ratio $\left(P_{F} / P_{U}\right)$ of fastened ALC section (Equation (5)).

$$
k_{f}=0.6\left(\frac{N h}{t^{2}}\right)^{a} \geq 1
$$

where the coefficient $a=0.126$ and 0.095 for the ETF and ITF loading conditions, respectively.

Figures 10(a) and (b) present all the experimental and numerical web crippling capacity ratios $\left(P_{F} / P_{U}\right)$ against the geometrical factor $N h / t^{2}$ for the ETF and ITF loading conditions, respectively. The mean values of the $P_{F} / P_{U}$ to the predicted $\left(k_{f}\right)$ ratios are 1.00 and 0.97 for the ETF and ITF loading conditions, respectively, while the corresponding COV values is 0.06 both loading conditions. This indicates the suitability of the new fastening factor approach to predict the increased web crippling capacity of wide-ranged fastened ALC sections under twoflange loading conditions.

\section{Current design rules}

\subsection{International specifications}

A detailed assessment to the accuracy of design guidelines recommended in the AS/NZS 1664.1 [31], AS/NZS 4600 [32] and Eurocode 3 [33] were conducted by comparing them with experimental and numerical parametric results. It should be mentioned that the predictions of the web crippling capacities using these specifications, apart of AS/NZS 4600 [32], are not differentiated between the sections with fastened and unfastened support conditions. Moreover, the design provisions given in Eurocode 9 [37] for aluminium sheeting structures were excluded herein due to their limitation to sections with multi-webs. The three specifications mentioned above are briefly introduced below outlining their respective prediction equations. 
5.1.1 AS/NZS 1664.1 [31] for aluminium structures

$$
\begin{aligned}
& P_{A S 1664}=\frac{1.2 t^{2} \sin \theta\left(0.46 f_{y}+0.02 \sqrt{E f_{y}}\right)\left(N+C_{w 2}\right)}{C_{w 3}+r_{i}(1-\cos \theta)} \\
& P_{A S 1664}=\frac{t^{2} \sin \theta\left(0.46 f_{y}+0.02 \sqrt{E f_{y}}\right)\left(N+C_{w 1}\right)}{C_{w 3}+r_{i}(1-\cos \theta)}
\end{aligned}
$$

where $C_{w 1}=140 \mathrm{~mm}, C_{w 2}=33 \mathrm{~mm}, C_{w 3}=10 \mathrm{~mm}, t$ is the web thickness, $N$ is the bearing length (mm), $r_{i}$ is the internal bent radius (mm); $E$ is the elastic modulus $(\mathrm{MPa}), f_{y}$ is the $0.2 \%$ static yield stress (MPa), and $\theta$ is the angle between the web surface and the bearing surface plane $\left(\theta=90^{\circ}\right)$.

\subsubsection{AS/NZS 4600 [32] for cold-formed steel structures}

$$
P_{A S 4600}=C t^{2} f_{y} \sin \theta\left(1-C_{R} \sqrt{\frac{r_{i}}{t}}\right)\left(1+C_{N} \sqrt{\frac{N}{t}}\right)\left(1-C_{h} \sqrt{\frac{h}{t}}\right)
$$

where $h$ is the flat portion of the web (mm); $C, C_{R}, C_{N}, C_{h}$ are the geometrical coefficients given in Table 5. Note that in Equation (6), the following conditions $h / t \leq 200, N / t \leq 210,{ }_{i} / t \leq$ $12, N / h \leq 2$, and $\theta=90^{\circ}$ must be satisfied.

5.1.3 Eurocodes 3 [33] for cold-formed steel structures

$$
\begin{gathered}
P_{E C 3}=\frac{k_{1} k_{2} k_{3} f_{y} t^{2}}{\gamma_{M 1}}\left[6.66-\frac{d_{w}}{64 t}\right]\left[1+0.01 \frac{N}{t}\right] \\
P_{E C 3}=\frac{k_{3} k_{4} k_{5} f_{y} t^{2}}{\gamma_{M 1}}\left[21-\frac{d_{w}}{16.3 t}\right]\left[1+0.0013 \frac{N}{t}\right]
\end{gathered}
$$

where:

$$
\begin{aligned}
& k_{1}=1.33-\frac{f_{y}}{690.9} \\
& k_{2}=1.15-0.15 \frac{r_{i}}{t}\left(0.5 \leq k_{5} \leq 1.0\right) \\
& k_{3}=0.7+0.3\left(\frac{\theta}{90}\right)^{2} \\
& k_{4}=1.22-\frac{f_{y}}{1036.4}
\end{aligned}
$$


$k_{5}=1.06-0.06 \frac{r_{i}}{t}\left(k_{5} \leq 1.0\right)$

$d_{w}$ is the web height between the flange mid-lines in $\mathrm{mm} ; \gamma_{M 1}$ is the partial safety factor $\left(\gamma_{M 1}=1\right)$ and $\theta$ is equal to $90^{\circ}$.

The mean and COV values of the web crippling capacities ratios $\left(P_{\text {Exp. }-F E A} / P_{\text {predicted }}\right)$ for the ETF and ITF loading conditions are summarised in Table 5. Generally, the design rules provided by the aforementioned specifications, apart from AS/NZS 1664.1 [31] for the ITF loading condition, overestimate the web crippling capacity of fastened ALC sections. The mean values of $P_{\text {Exp. }}$ FEA $/ P_{\text {predicted }}$ ratios are ranging from 0.55 to 0.87 with the $\mathrm{COV}$ values between 0.11 and 0.26 for both the ETF and ITF loading conditions. The AS/NZS 1664.1 [31] predictions agree reasonably well for the ITF loading condition with the mean and COV values equalling 1.04 and 0.13, respectively. Figures 11 (a) and (b) show the comparisons between the predicted capacities $\left(P_{\text {predicted }}\right)$ obtained from the current design guidelines and the ultimate web crippling capacity capacities $\left(P_{E x p .}-F E A\right)$ under the ETF and ITF loading conditions, respectively.

\subsection{Modified design rules}

Alsanat et al. [28] improved the accuracy of the design rules obtained from the AS/NZS 1664.1 [31], AS/NZS 4600 [32] and Eurocode 3 [33] specifications for unfastened ALC sections by modifying them based on experimental tests, in which the test specimens had their $h / t$ ranging from 30 to $100, r_{i}=5 \mathrm{~mm}$ and the aluminium alloy grade being $5052 \mathrm{H} 36$. In this study, comparisons between the predictions of the modified Equations (11)-(15) (where $k_{f}$ is the fastening factor according to Equation (5) and the wide-ranged parametric and experimental data for fastened ALC sections were carried out.

\subsubsection{Modified AS/NZS 1664.1}

$$
\begin{gathered}
P_{A S 1664 \text { (Modi.) }}=k_{f} \frac{C_{1} t^{2} \sin \theta\left(0.46 f_{y}+0.02 \sqrt{E f_{y}}\right)\left(N+C_{w 2}\right)}{C_{w 3}+r_{i}(1-\cos \theta)}\left(1-C_{h 1} \sqrt{\frac{h}{t}}\right) \\
P_{A S 1664 \text { (Modi.) }}=k_{f} \frac{C_{2} t^{2} \sin \theta\left(0.46 f_{y}+0.02 \sqrt{E f_{y}}\right)\left(N+C_{w 1}\right)}{C_{w 3}+r_{i}(1-\cos \theta)}\left(1-C_{h 2} \sqrt{\frac{h}{t}}\right)
\end{gathered}
$$


where $C_{1}=0.31, C_{2}=258, C_{w 1}=780 \mathrm{~mm}, C_{w 2}=238 \mathrm{~mm}, C_{w 3}=10 \mathrm{~mm}, C_{h 1}=0.05$ and $C_{h 2}=$ 0.025 .

\subsubsection{Modified AS/NZS 4600}

$$
P_{A s 4600 \text { (modi. })}=k_{f} C t^{2} \sqrt{E f_{y}} \sin \theta\left(1-C_{R} \sqrt{\frac{r_{i}}{t}}\right)\left(1+C_{N} \sqrt{\frac{N}{t}}\right)\left(1-C_{h} \sqrt{\frac{h}{t}}\right)
$$

where the values of the proposed geometrical coefficients are summarised in Table 5.

\subsubsection{Modified EC3}

$$
\begin{aligned}
& P_{E C 3(\text { Modi. })}=k_{f} \frac{0.028 k_{1} k_{2} k_{3} \sqrt{E f_{y}} t^{2}}{\gamma_{M 1}}\left[6.66-\frac{d_{w}}{64 t}\right]\left[1+0.01 \frac{N}{t}\right] \\
& P_{E C 3(\text { Modi. })}=k_{f} \frac{0.034 k_{3} k_{4} k_{5} \sqrt{E f_{y}} t^{2}}{\gamma_{M 1}}\left[21-\frac{d_{w}}{16.3 t}\right]\left[1+0.0013 \frac{N}{t}\right]
\end{aligned}
$$

The mean and COV values of the web crippling capacity ratios $\left(P_{\text {Exp. }}-F E A / P_{\text {predicted }}\right)$ using the modified Equations (11)-(15) are summarised in Table 6 for the ETF and ITF loading conditions. The comparison shows that the modified equations are able to accurately predict the web crippling capacity for both loading conditions with reasonable mean and COV values ranging from 0.99 to 1.10 and 0.05 to 0.10 , respectively. It can be concluded that the web crippling capacity formulae incorporating the fastening factor can accurately predict the increased capacities of the ALC sections under two-flange loading conditions when the flanges are restrained to the supports as shown in Figures 12 (a) and (b).

\section{Direct strength method}

Schafer [38] developed the Direct Strength Method (DSM) approach to determine the ultimate capacity of thin-walled members. This method has been successfully employed to estimate the capacity of cold-formed steel member under compression, bending and shear actions based on their elastic and yield capacities. However, further improvement to this method is still needed for the web crippling design of thin-walled aluminium members. In this study, the DSM-based design equations are proposed for predicting the web crippling capacities $\left(P_{n}\right)$ of fastened ALC sections under two-flange loading conditions, based on the results from experiments [30] and 
those obtained from the present numerical parametric analyses. For this purpose, critical buckling and yield loads of fastened ALC sections are determined by the FE elastic buckling analysis and the Yield-Line Theory (YLT), respectively.

\subsection{Elastic buckling load}

The elastic buckling load for conventional plates is generally determined using Equation (16). However, such approach is rather inaccurate in predicting the elastic capacity of lipped channel sections due to the complex interaction between the web, flanges and corners elements and therefore numerical elastic buckling analysis is often implemented instead. In this study, ABAQUS was employed to conduct elastic buckling analyses to estimate the critical buckling loads of fastened ALC sections under ETF and ITF loading conditions.

$$
P_{c r}=\frac{\pi^{2} E k_{c r} t^{3}}{12\left(1-v^{2}\right) d}
$$

where $k_{c r}$ is the buckling coefficient and $v$ is the the Poisson ratio ( 0.33 for aluminium $)$.

Figure 13 shows the established numerical models with the associated boundary conditions to predict the critical buckling load of fastened ALC sections under the ETF and ITF loading conditions. The bottom flange at the supports was prevented from translational movement in all directions (displacements $U_{x}, U_{y}$, and $U_{z}$ ) for both loading conditions. For the loaded area on the top flange, Reference Point (RP) was implemented with MPC rigid tie connections to assign the boundary conditions ( $U_{x}, U_{z}, R_{y}$, and $R_{z}$ were fixed), and a unit load was assigned to the vertical direction $\left(U_{y}\right)$. The Subspace Eigen Extraction method was used in the linear analysis, and the first Eigen mode (minimum buckling capacity) was selected. A total of thirtyeight numerical models were simulated for the ETF and ITF loading conditions and their elastic buckling capacities $P_{c r(F E M)}$ are summarised in Tables 7 and 8, respectively.

The elastic critical buckling loads obtained from the numerical analyses were used to calculate the elastic buckling coefficient $\left(k_{c r(F E A)}\right)$ using Equation (16), and the results are summarised in Tables 7 and 8, for the ETF and ITF loading conditions, respectively. The coefficient $k_{c r}$ is typically influenced by both sectional geometry and the bearing length, and hence can be expressed using empirical expressions. A linear relationship was found between $k_{c r(F E A)}$ and the bearing length to section height ratio $(N / d)$, as shown in Figure 14. Thus, a simplified approach (Equation (17)) was developed in this study to determine the elastic buckling coefficients $\left(k_{c r}\right.$ (Prop.) $)$ of the fastened ALC sections under both loading conditions.

$$
k_{c r(\text { Prop. })}=C_{b, 1}+C_{b, 2} \frac{N}{d}
$$


where $C_{b, 1}=1$ and $C_{b, 2}=3$ for the ETF loading condition, and $C_{b, 2}=3.4$ and $C_{b, 2}=2$ for the ITF loading condition.

The FE buckling loads $\left(P_{c r(F E M)}\right)$ and the proposed buckling loads $\left.\left(P_{c r(P r o p .}\right)\right)$, calculated by substituting Equation (15) into Equation (16), are compared in Tables 7 and 8 for the ETF and ITF loading conditions, respectively. The mean value of $P_{c r(F E M)} / P_{c r(P r o p .)}$ is 1.00 for both loading conditions, whereas the corresponding COV values are 0.03 and 0.02 . This indicates that the proposed elastic buckling load $\left.\left(P_{c r(P r o p .}\right)\right)$ incorporating the fastening factor agrees well with the corresponding numerical bucking load $\left(P_{c r(F E M)}\right)$ for fastened ALC sections under both ETF and ITF loading conditions.

\subsection{Yield load}

Determining the yield load $\left(P_{y}\right)$ is the other key aspect of the DSM-based design method in addition to the buckling load $\left(P_{c r}\right)$. Generally, simplified approaches can be used for beams, columns, beam-columns under global, distortional and local buckling modes. However, for members under web crippling actions, highly localised deformations and the associated nonuniform stresses further obscure the definition of the yield load. Natário et al. [39, 40] thoroughly investigated the plastic mechanism of different cold-formed steel sections including built-up I-section, Z- section (fastened/unfastened), C-section (unlipped/lipped and fastened/unfastened) under the ETF and ITF loading conditions. Analytical expressions were derived based on the yield-line models, and Equations (18) and (21) were developed [39, 40] to determine the yield capacity of fastened lipped channel sections under the ETF and ITF loading conditions, respectively.

For the ETF loading condition,

$$
\begin{gathered}
P_{y}=f_{y} N_{m}\left(-2 r_{m}+\sqrt{4 r_{m}^{2}+t^{2} \frac{N^{*}}{N_{m}}}\right) \\
N^{*}=2 N_{m}+\frac{4}{\sqrt{3}}\left(h+2 r_{m}\right) \\
N_{m}=N+2.5 r_{\text {ext }}+(h / 2)
\end{gathered}
$$

For the ITF loading condition,

$$
\begin{array}{r}
P_{y}=\frac{1}{2} f_{y} N_{m}\left(\sqrt{16 r_{m}^{2}+6 t^{2}}-4 r_{m}\right) \\
N_{m}=\min \left(L ; N+5 r_{\text {ext }}+3 h\right)
\end{array}
$$


where $N_{m}$ is the length of yield line (mm), $N^{*}$ is an auxiliary parameter (length in yield-line method) (mm), $r_{\text {ext }}$ is the external bent radius $(\mathrm{mm})$ and $r_{m}$ is the midline bent radius $(\mathrm{mm})$.

These formulae are employed in this study to calculate the yield load of fastened ALC sections under both loading conditions. Figure 15 display the typical plastic failure mechanism proposed by Natário et al. $[39,40]$ as well as von-Mises stress distributions observed at the ultimate failure stage for the ETF and ITF loading conditions.

\subsection{Proposed Direct Strength method (DSM)-based approach}

In this research, a DSM-based approach is developed based on the elastic buckling load $\left(P_{c r}\right)$ (Section 6.1), the yield load $\left(P_{y}\right)$ (Section 6.2), and the experimental as well as numerical data for fastened ALC sections under the ETF and ITF loading conditions. Using a non-linear regression procedure, the DSM-based formulae (Equations (23) and (24)) were calibrated to estimate the web crippling strength $\left(P_{n}\right)$ of fastened ALC sections under both loading conditions.

For the ETF loading condition:

$$
P_{n}=\left\{\begin{array}{l}
P_{y} \quad \text { for } \lambda \leq 0.2 \\
0.3 P_{y}\left[1-0.07\left(\frac{P_{c r}}{P_{y}}\right)^{0.52}\right]\left(\frac{P_{c r}}{P_{y}}\right)^{0.52} \text { for } \lambda>0.2
\end{array}\right.
$$

For the ITF loading condition:

$$
P_{n}=\left\{\begin{array}{l}
P_{y} \quad \text { for } \lambda \leq 0.34 \\
0.55 P_{y}\left[1-0.138\left(\frac{P_{c r}}{P_{y}}\right)^{0.58}\right]\left(\frac{P_{c r}}{P_{y}}\right)^{0.58} \text { for } \lambda>0.34
\end{array}\right.
$$

where $\lambda$ is the web crippling slenderness $\left(\lambda=\sqrt{P_{y} / P_{c r}}\right)$.

Figures 16 (a) and (b) compare the load ratio $P_{n} / P_{y}$ against the web crippling slenderness $(\lambda)$. A clear trend signifying the relationship between $P_{n} / P_{y}$ and $\lambda$ can be seen for both the ETF and ITF loading conditions. This generally indicates the reliability of the proposed elastic buckling coefficient (Equation (17)), and the suitability of the yield-line theory developed by Natário et al. $[39,40]$ for determining the yield load $\left(P_{y}\right)$ for cold-formed steel members to be applied to aluminium members. Further, having no data points closer to the plastic plateau $\left(P_{n} / P_{y}=1\right)$ implies that the ALC sections are primarily governed by buckling failure and a combination of buckling and plastic failure due to the low value of elastic modulus. Table 6 gives the mean 
values of the ultimate-to-DSM predicted capacity ratios as 1.01 and 1.01, while the corresponding COV values are 0.11 and 0.13 for the ETF and ITF loading conditions, respectively.

\section{$7 \quad$ Reliability analysis}

The statistical model recommended by the North American Specification [41] are generally used to calculate the capacity resistance factor $\left(\phi_{w}\right)$. The variation of material, fabrication and loading effects is considered in this model (Equation (25)).

$$
\phi_{w}=1.5 M_{m} F_{m} P_{m} e^{-\beta_{0} \sqrt{V_{M}^{2}+V_{F}^{2}+C_{n} V_{P}^{2}+V_{Q}^{2}}}
$$

where $P_{m}$ and $V_{p}$ are the mean value and the COV of the test-to-predicted load ratio, respectively, $F_{m}$ and $V_{F}=1.0,0.05$ are the mean value and COV of the fabrication factor, respectively, $M_{m}, V_{M}=1.1,0.06$ are the mean value and $\mathrm{COV}$ of the material factor, respectively, $V_{Q}=0.21$ is the $\mathrm{COV}$ of the load effect, $C_{n}=n^{2}-1 / n^{2}-3 n$ is the correction factor depending on the number of tests $n$ and $\beta_{0}$ is the target reliability index for beams $\left(\beta_{0} \geq\right.$ 2.5).

Table 6 gives the respective resistance factor $\left(\phi_{w}\right)$ and reliability indexes $\left(\beta_{0}\right)$ for the predictions of the international design rules, modified equations and proposed DSM formulae. The results showed that the reliability indexes $\left(\beta_{0}\right)$ calculated based on the recommended resistance factors $\left(\phi_{w}\right)$ given in the international specifications are less that the target value $\left(\beta_{0}<2.5\right)$ which indicates their unreliability. However, the reliability indexes $\left(\beta_{0}\right)$ for the modified and proposed DSM equations and based on our recommend resistance factors $\left(\phi_{w}\right)$ are equal or exceed the target value $\left(\beta_{0} \geq 2.5\right)$. Hence, it is suggested to use $\phi_{w}=0.90$ for all modified equations, except Equation 12, and $\phi_{w}=0.85$ for the proposed DSM-based approach as well as Equation (12).

\section{Conclusions}

This paper describes a numerical study of fastened roll-formed ALC sections under web crippling action with two-flange loading conditions. 38 numerical models were firstly developed and validated with the results of the experimental study conducted by the authors in the past. A comprehensive parametric study was then conducted to further study the influence of various parameters including sectional geometries, bearing lengths and aluminium alloy grades on the web crippling capacities. The acquired large database containing numerical and 
previous experimental results was then used to explore the effect of restrained flanges on the web crippling capacity of the ALC sections. The web crippling capacities of these sections have increased due to flange restraining up to $88 \%$ and $45 \%$ under the ETF and ITF loading conditions, respectively. Both the accuracy and reliability of the current design rules recommended by the international specifications as well as the modified equations with the association of the proposed fastening factor were evaluated. It was found that the design rules specified in the current international guidelines are unsafe with a large coefficient of variation to estimate the web crippling capacities, apart of AS/NZS 1664.1 for the ITF loading condition. On the other hand, the modified equations can accurately predict the web crippling capacity of fastened ALC sections. The development of DSM-design approach for fastened roll-formed aluminium sections is also presented in this study. The elastic buckling analyses were carried out, and a predictive approach was proposed to estimate the buckling load. Further, the existing analytical expressions derived based on the Yield-Line Theory to determine the plastic load for cold-formed steel members were found to be suitable and applicable for fastened ALC sections. The outcomes of this study can be considered for potential inclusion in the relevant international specifications to improve the accuracy and reliability of the design rules.

\section{Acknowledgements}

The authors are grateful to Griffith University for providing the necessary technical support and test facilities to conduct this project, and to Mr Robert Price from BlueScope Building Components Pty Ltd for supplying the test specimens.

\section{References}

[1] Mazzolani FM. Structural applications of aluminium in civil engineering. Struct Eng Intern 2006;16(4):280-5.

[2] American Iron and Steel Institute. Standard test method for determining the web crippling strength of cold-formed steel beams. AISI S909, Washington DC, USA; 2008.

[3] Bock M, Theofanous M, Dirar S, Raybone P. Assessment of web crippling design provisions for application to proprietary soldier beams. Struct 2019;20:147-56.

[4] Gunalan S, Mahendran M. Web crippling tests of cold-formed steel channels under two flange load cases. J Const Steel Res 2015;110:1-15.

[5] Gunalan S, and Mahendran M. .Experimental study of unlipped channel beams subject to web crippling under one flange load cases. Adv Steel Constr 2019;15(2):165-72. 
[6] Sundararajah L, Mahendran M, Keerthan P. New design rules for lipped channel beams subject to web crippling under two-flange load cases. Thin-Walled Struct 2017;119:421-37.

[7] Sundararajah L, Mahendran M, Keerthan P. Experimental studies of lipped channel beams subject to web crippling under two-flange load cases. J Struct Eng 2016;142(9): :04016058.

[8] Sundararajah L, Mahendran M, Keerthan P. Web crippling studies of SupaCee sections under two flange load cases. Eng Struct 2017;153:582-97.

[9] Keerthan P, Mahendran M, Steau E. Experimental study of web crippling behaviour of hollow flange channel beams under two flange load cases. Thin-Walled Struct 2014;85:207-19.

[10] Uzzaman A, Lim JBP, Nash D, Rhodes J, and Young B. Cold-formed steel sections with web openings subjected to web crippling under two-flange loading conditionsPart I: Tests and finite element analysis. Thin-Walled Struct 2012;56:38-48.

[11] Uzzaman A, Lim JBP, Nash D, Rhodes J, and Young B. Web crippling behaviour of cold-formed steel channel sections with offset web holes subjected to interior-twoflange loading. Thin-Walled Struct 2012;50(1):76-86.

[12] Steau E, Mahendran M, Keerthan P. Web crippling tests of rivet fastened rectangular hollow flange channel beams under two flange load cases. Thin-Walled Struct 2015;95:262-275.

[13] Steau E, Keerthan P, Mahendran M. Web crippling capacities of rivet fastened rectangular hollow flange channel beams under one flange load cases. Steel Constr 2016;9(3):222-239.

[14] Bhakta BH, LaBoube RA, Yu WW. The effect of flange restraint on web crippling strength. Final report, University of Missouri-Rolla, Rolla, MO, USA; 1992.

[15] Gerges RR, and Schuster RM. Web crippling of single web cold formed steel members subjected to end one-flange loading. Proceedings of the 14th International specialty conference on cold-formed steel structures; 1998 October. 1998. Missouri, U.S.A.

[16] Macdonald M, Don MH, KoteŁko M, Rhodes J. Web crippling behaviour of thinwalled lipped channel beams. Thin-Walled Struct 2011;49(5):682-90. 
[17] Janarthanan B, Mahendran M, and Gunalan S. Bearing capacity of cold-formed unlipped channels with restrained flanges under EOF and IOF load cases. Steel Constr 2015;8(3):146-154.

[18] Janarthanan B, Mahendran M, and Gunalan S. Numerical modelling of web crippling failures in cold-formed steel unlipped channel sections. J. Constr Steel Res 2019;158:486-501.

[19] Janarthanan B, Sundararajah L, Mahendran M, Keerthan P, and Gunalan S. Web crippling behaviour and design of cold-formed steel sections. Thin-Walled Struct 2019;140:387-403.

[20] Beshara B, and Schuster R M. Web crippling of cold formed steel C- and Z- sections. . Proceedings of the 15th International specialty conference on cold-formed steel structures, Department of Civil Engineering Center for Cold- Formed Steel Structures; 2000. Rolla, MO.

[21] Wang YQ, Wang ZX, Yin FX, Yang L, Shi YJ, Yin J. Experimental study and finite element analysis on the local buckling behavior of aluminium alloy beams under concentrated loads. Thin-Walled Struct 2016;105:44-56.

[22] Zhou F. and Young B. "Aluminium alloy channels subjected to web crippling." Adv in Struct Eng 2019; 22(7), 1617-1630.

[23] Zhou F, Young B. Aluminum tubular sections subjected to web crippling-Part I. ThinWalled Struct 2008;46(4):339-51.

[24] Young B, Zhou F. Aluminium tubular sections subjected to web crippling-Part II: Proposed design equations. Thin-Walled Struct 2008;46(4):352-361.

[25] Zhou F, Young B, Zhao X.L. Tests and design of aluminium tubular sections subjected to concentrated bearing load. J Struct Eng 2009;135(7):816-817.

[26] Chen Y, Chen X, Wang C. Aluminum tubular sections subjected to web crippling. ThinWalled Struct 2015;90:49-60.

[27] Su MN, Young B. Design of aluminium alloy stocky hollow sections subjected to concentrated transverse loads. Thin-Walled Struct 2018;124:546-57.

[28] Alsanat H, Gunalan S, Guan H, Keerthan P, Bull J. Experimental study of aluminium lipped channel sections subjected to web crippling under two flange load cases. ThinWalled Struct 2019;141:460-476. 
[29] Alsanat H, Gunalan S, Guan H, Keerthan P, K. \& Tsavdaridis K. D. Web crippling behaviour and design for aluminium lipped channel sections under two flange loading conditions. Thin-Walled Struct 2019; 144:106265.

[30] Alsanat H, Gunalan S, Poologanathan K, Guan H, Baniotopoulos C. Web Crippling for fastened aluminium lipped channel sections under two flange loading conditions. J Struct Eng 2019. (in press)

[31] Standards Australia/Standards New Zealand. Australia/New Zealand Standard AS/NZS 1664.1 Aluminium structures - Part 1: Limit state design. Sydney, Australia; 1997.

[32] Standards Australia/Standards New Zealand. Australia/New Zealand Standard AS/NZS 4600 Cold-formed steel structures. Sydney, Australia; 2018.

[33] EN 1993-1-3. Eurocode 3: Design of steel structures - part 1-3: general rules supplementary rules for cold-formed members and sheeting. European Committee for Standardization, Brussels; 2006.

[34] Simulia. ABAQUS Standard User's Manual, Version 6.14, Rhode Island, USA; 2013.

[35] Natário P, Silvestre N, Camotim D. Web crippling failure using quasi-static FE models. Thin-Walled Struct 2014;84:34-49.

[36] Su MN, Young B. Design of aluminium alloy stocky hollow sections subjected to concentrated transverse loads. Thin-Walled Struct 2018;124:546-57.

[37] EN 1999-1-4. Eurocode 9: Design of aluminium structures - Part 1.4: Cold-formed structural sheeting. European Committee for Standardization, Brussels; 2007.

[38] Schafer BW. The direct strength method of cold-formed steel member design. J Constr Steel Res 2008;64(7-8):766-78.

[39] Natário P, Silvestre N, Camotim D. Direct strength prediction of web crippling failure of beams under ETF loading. Thin-Walled Struct 2016;98:360-74.

[40] Natário P, Silvestre N, Camotim D. Web crippling of beams under ITF loading: A novel DSM-based design approach. J Const Steel Res 2017;128:812-24.

[41] American Iron and Steel Institute (AISI). Specifications for the cold-formed steel structural members, cold-formed steel design manual. AISI S100, Washington DC, USA; 2012. 


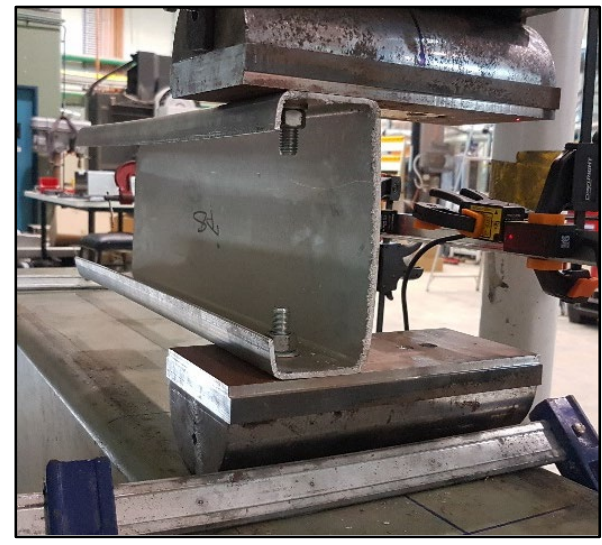

(a) ETF test

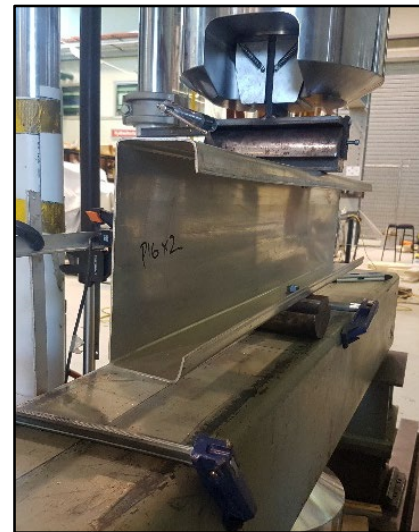

(b) ITF test

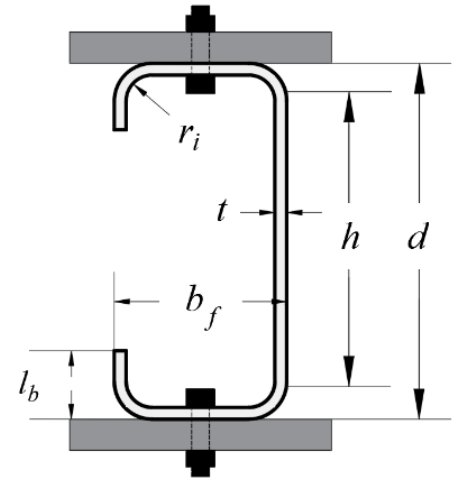

(c) Cross section profile

Figure 1: Fastened web crippling test set-up and ACL section profile [30]

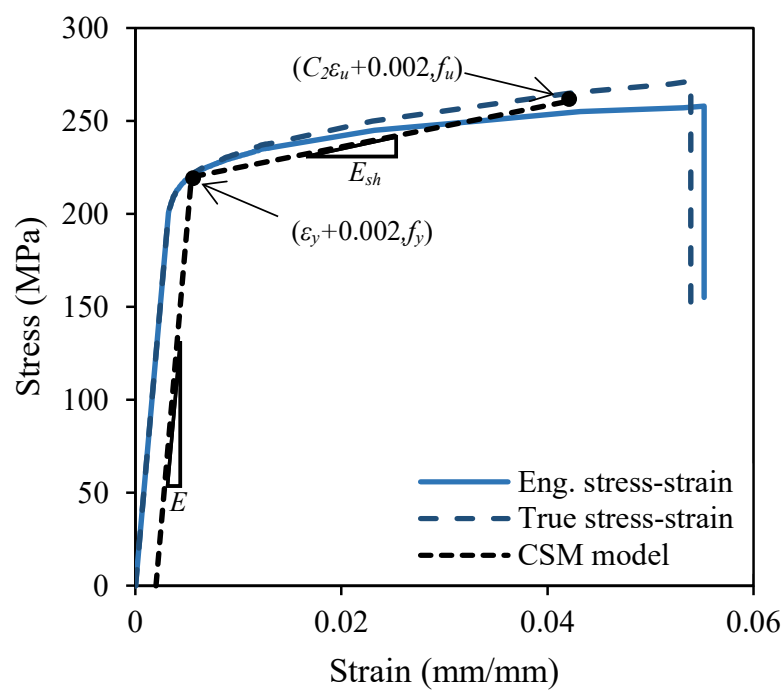

Figure 2: Typically measured stress-strain curve and bi-linear CSM model [36] for 5052-H36 aluminium alloy 


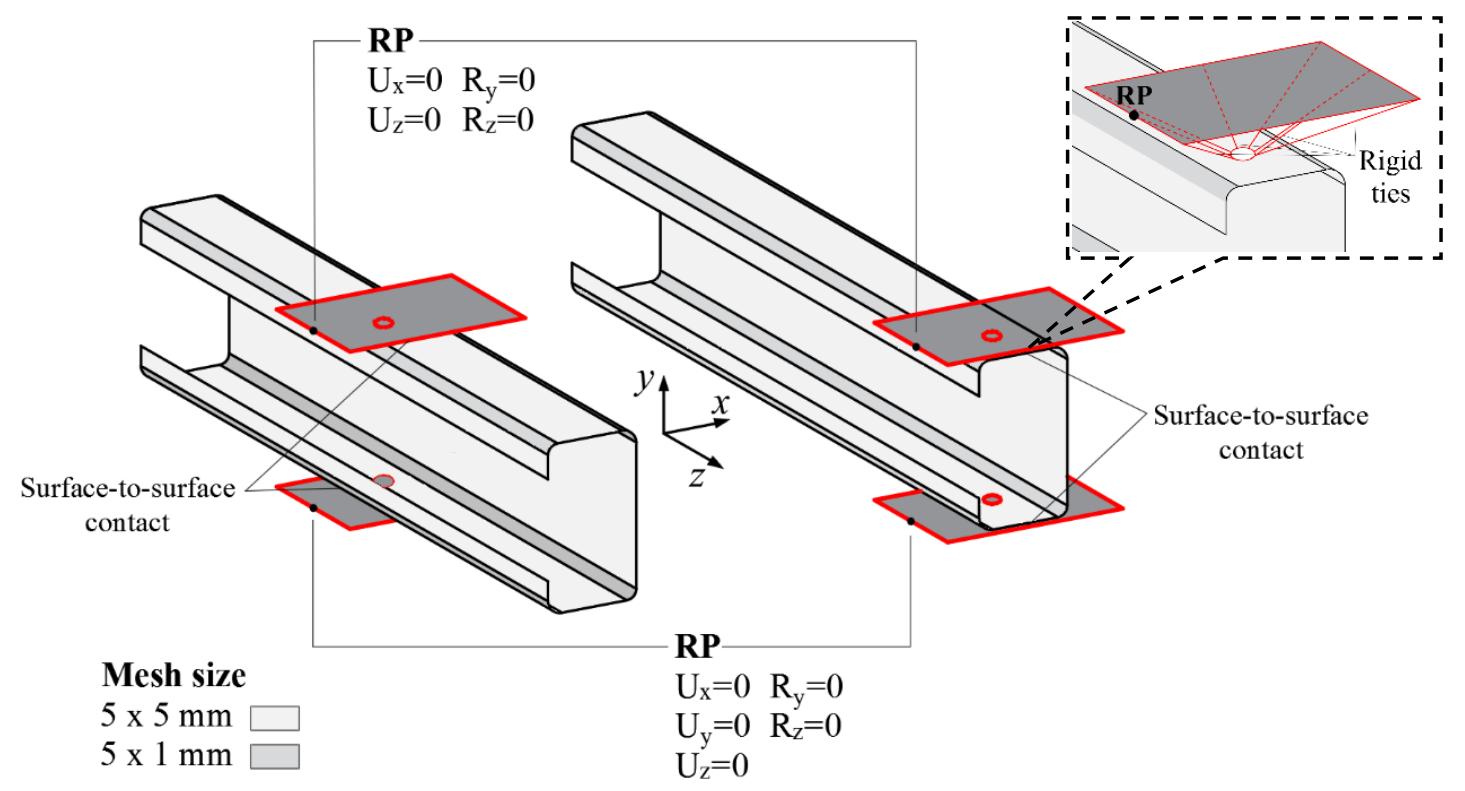

Figure 3: Overview of the assigned boundary conditions and mesh size distributions in the web crippling models (RP: Reference Point) 


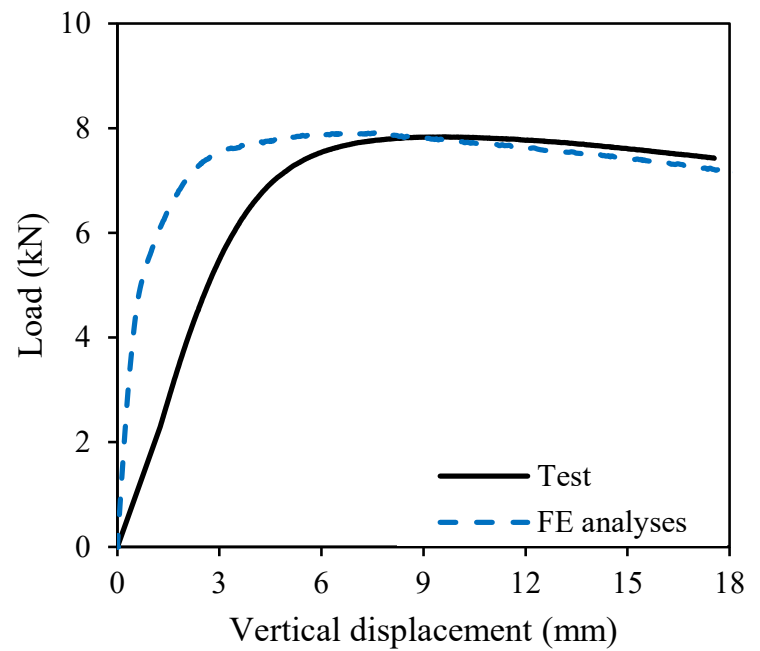

(a) ETF-15030-N50

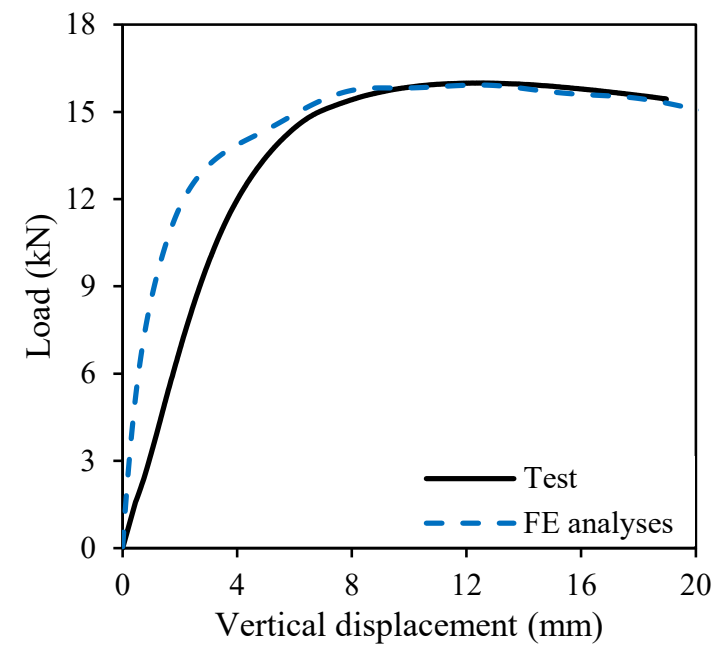

(b) ITF-25025-N100

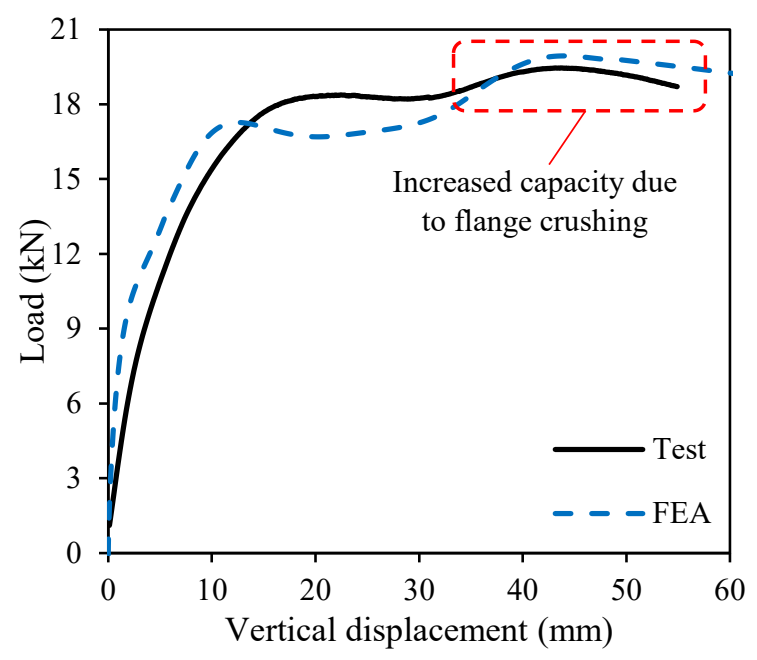

(c) ITF-20030-N25

Figure 4: Comparison of experimental and numerical load versus vertical displacement curves 


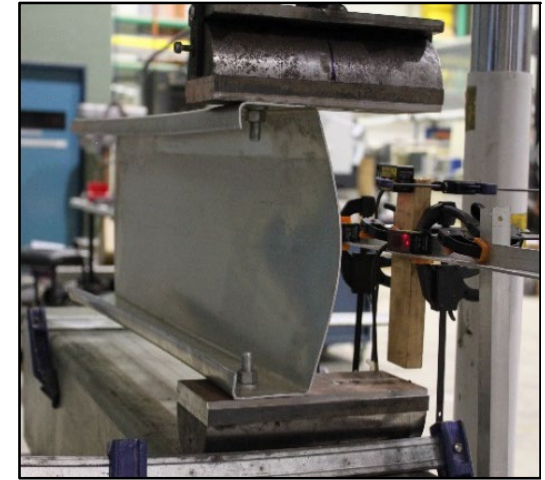

Test specimen

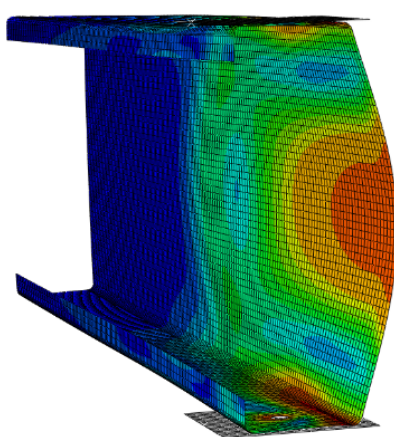

FE model

(a) ETF-25025-N100 (web crippling)

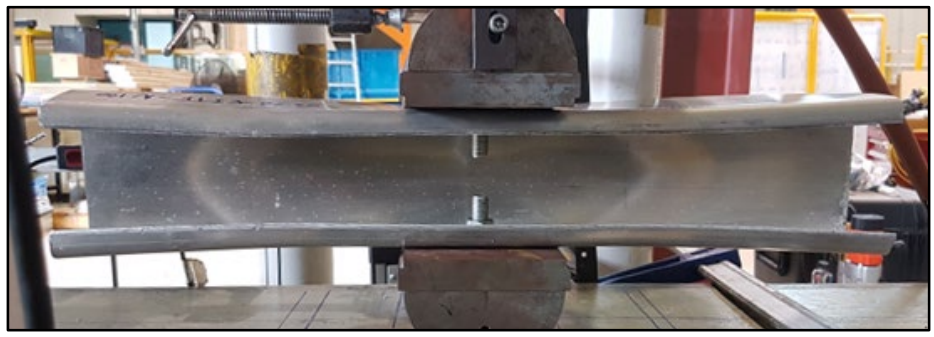

Test specimen

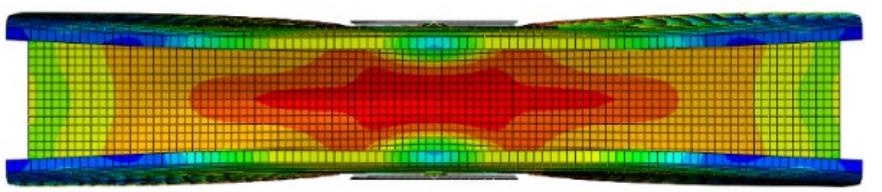

FE model

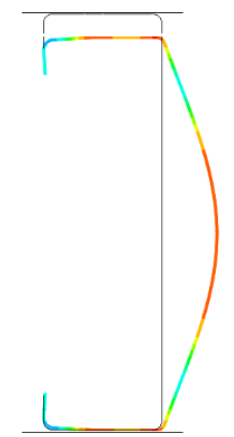

FE cross section

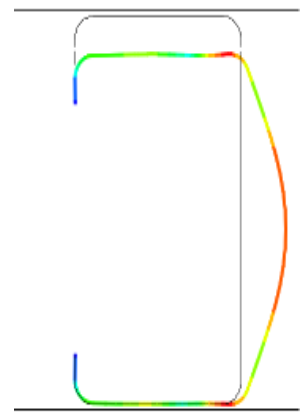

FE cross section

(b) ITF-10030-N100 (web crippling)

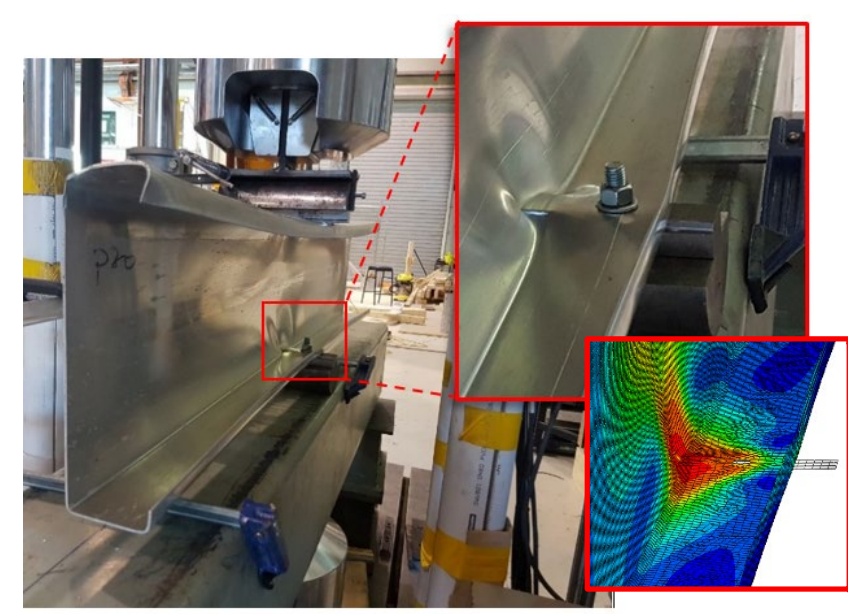

Test specimen

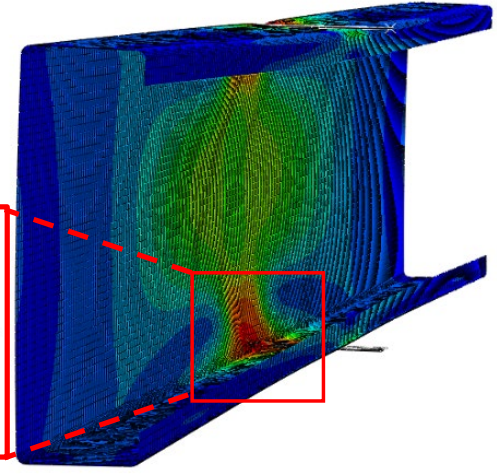

FE model

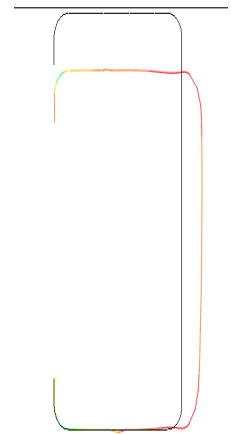

FE cross section

(c) ITF-25025-N25 (flange crushing)

Figure 5: Comparison of experimental and numerical failure modes 

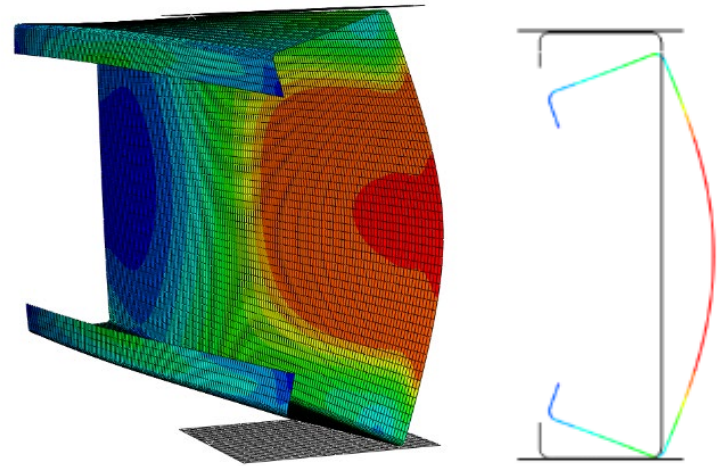

(a) Unfastened
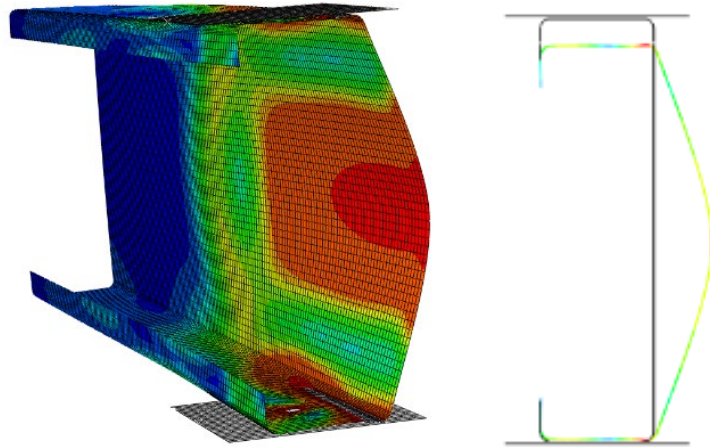

(b) Fastened

Figure 6: Web crippling failure modes for unfastened and fastened specimens

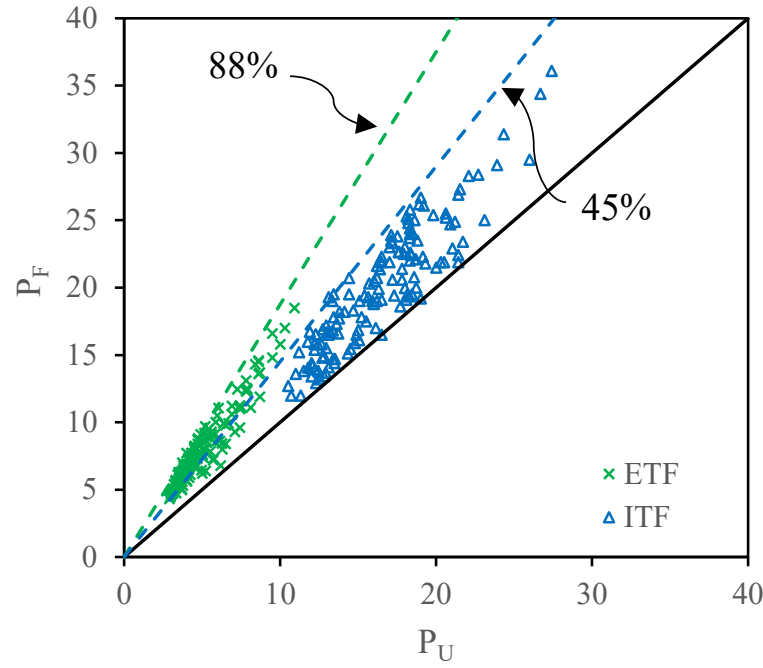

Figure 7: Comparison between the web crippling failure capacities of fastened $\left(P_{F}\right)$ and unfastened $\left(P_{U}\right)$ models 


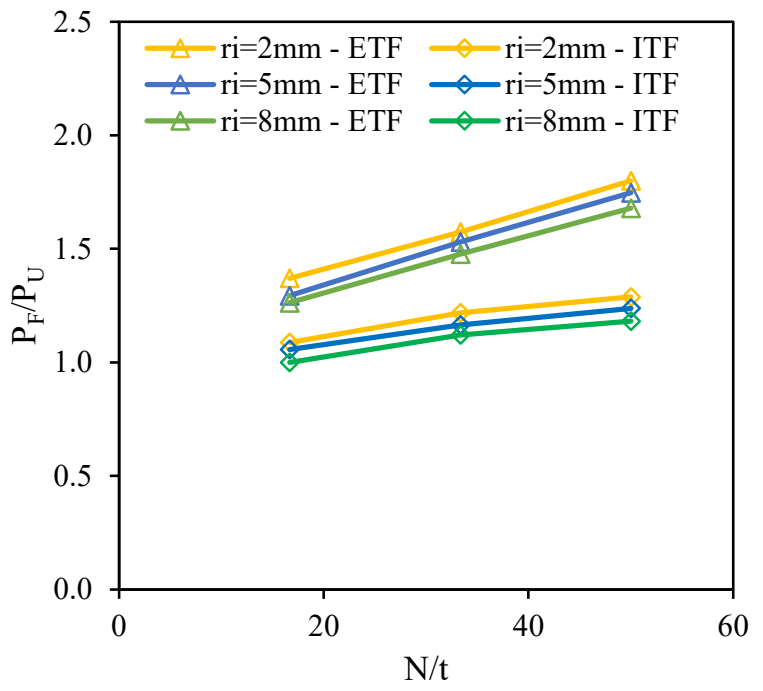

Figure 8: Web crippling capacity ratio $\left(P_{F} / P_{U}\right)$ versus bearing length ratio $(N / t)$ with different inside bent radii (models with $h / t=32$ and $f_{y}=179 \mathrm{MPa}$ )

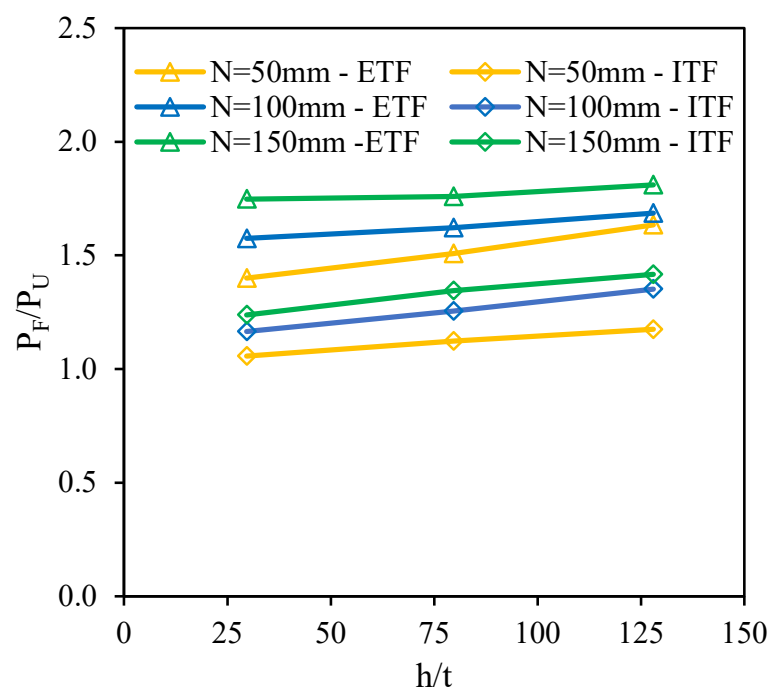

Figure 9: Web crippling capacity $\left(P_{F} / P_{U}\right)$ versus web slenderness ratio $(h / t)$ with different bearing lengths (models with $r_{i}=5 \mathrm{~mm}$ and $f_{y}=179 \mathrm{MPa}$ ) 


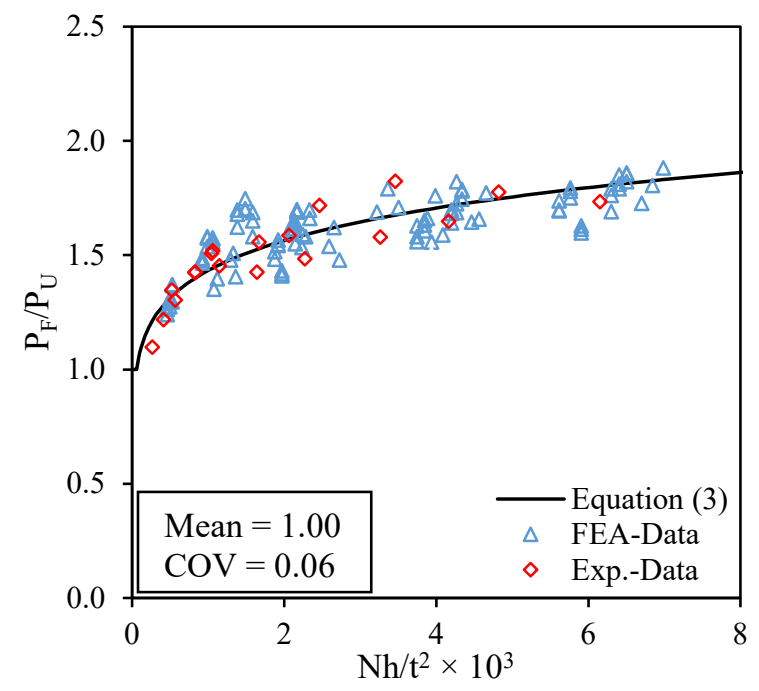

(a) ETF loading condition

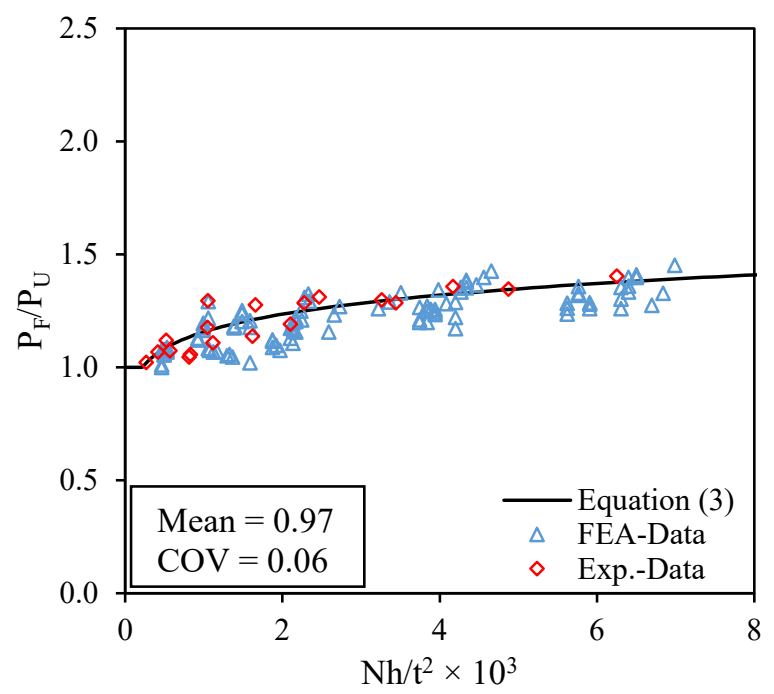

(b) ITF loading condition

Figure 10: Influence of fastened-to-unfastened capacity $\left(P_{F} / P_{U}\right)$ against the geometrical factor $N h / t^{2}$ 


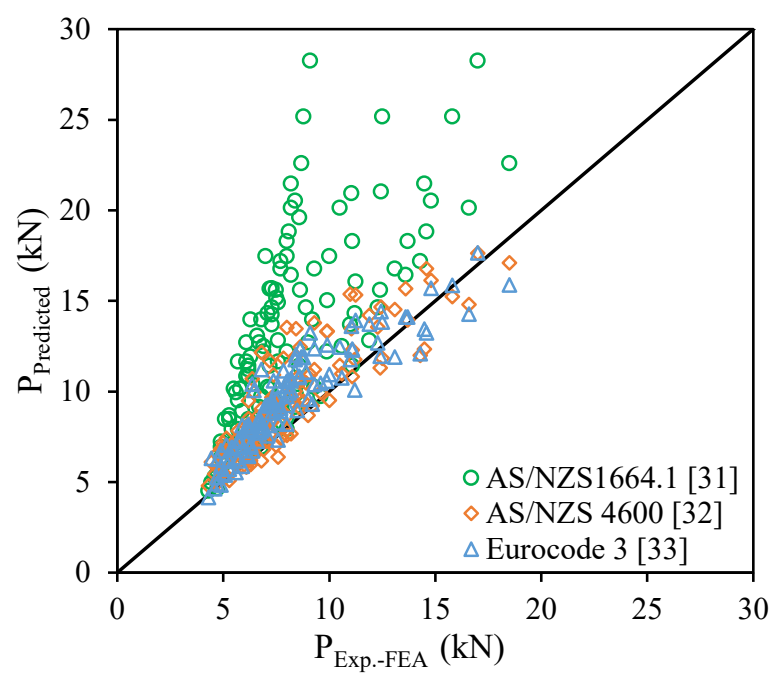

(a) ETF loading condition

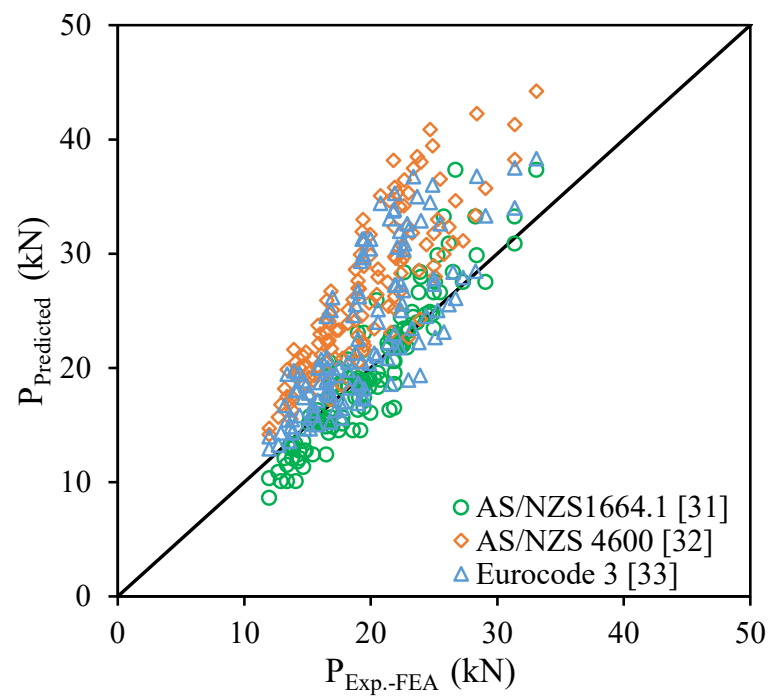

(b) ITF loading condition

Figure 11: Comparison between experimental and numerical web crippling capacities and predictions of current international specifications 


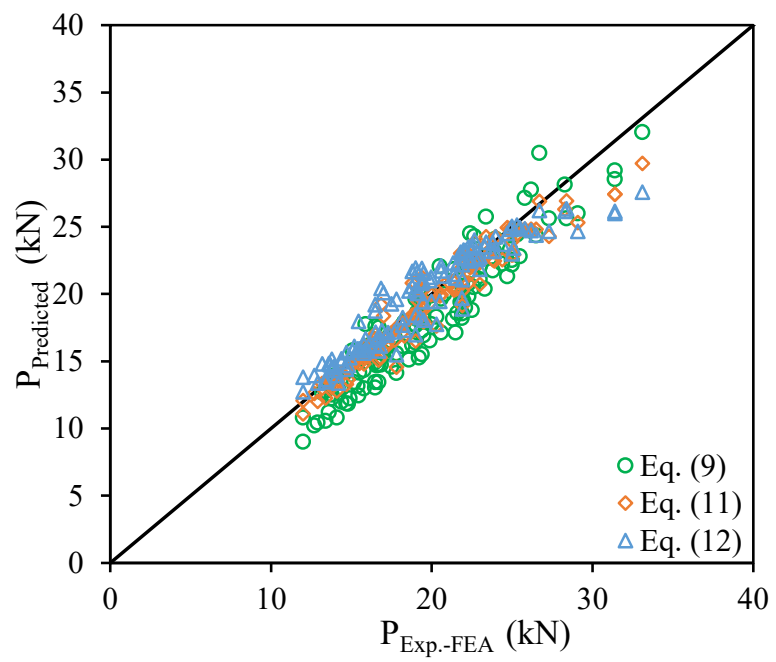

(a) ETF loading condition

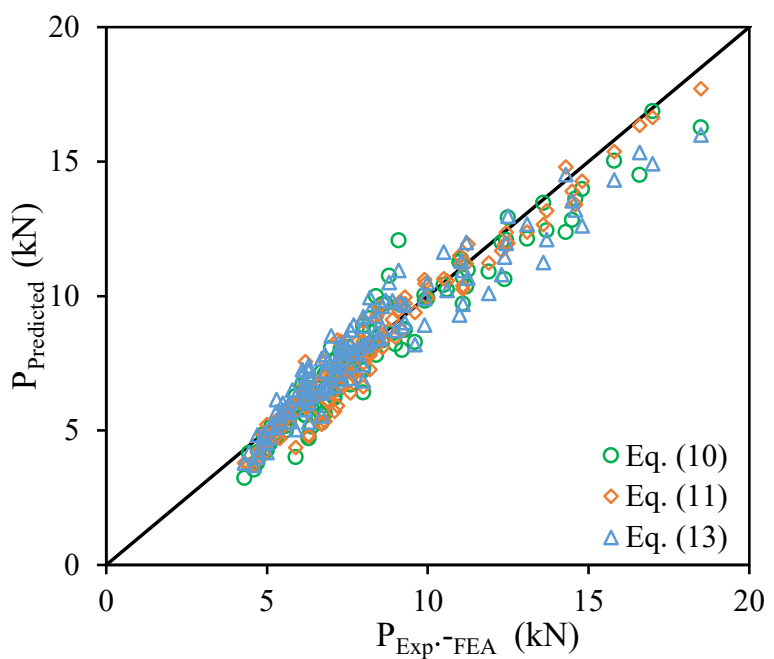

(b) ITF loading condition

Figure 12: Comparison between experimental and numerical web crippling capacities and predictions of modified equations (Equations (9-13)) 


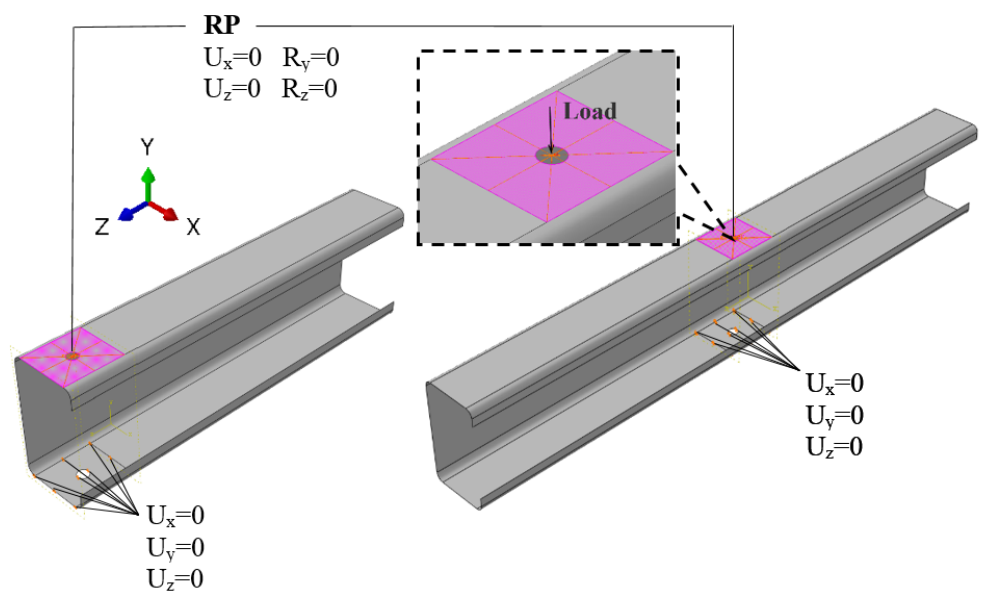

Figure 13: Assigned boundary conditions in the buckling model for fastened ALC sections

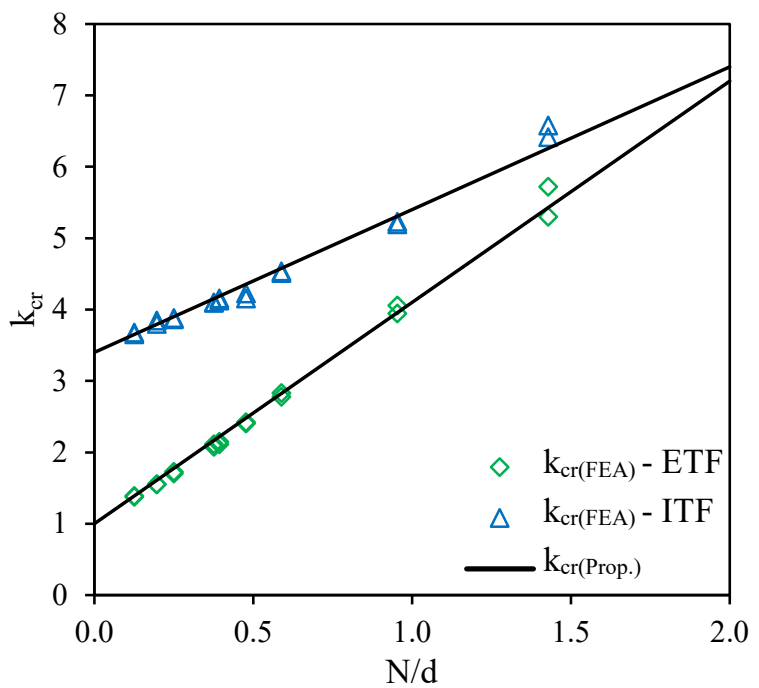

Figure 14: Comparison between the proposed elastic buckling coefficients ( $\left.k_{c r(P r o p .)}\right)$ and FEA elastic buckling coefficients $\left(k_{c r(F E A)}\right)$ for different $\mathrm{N} / \mathrm{d}$ ratios 

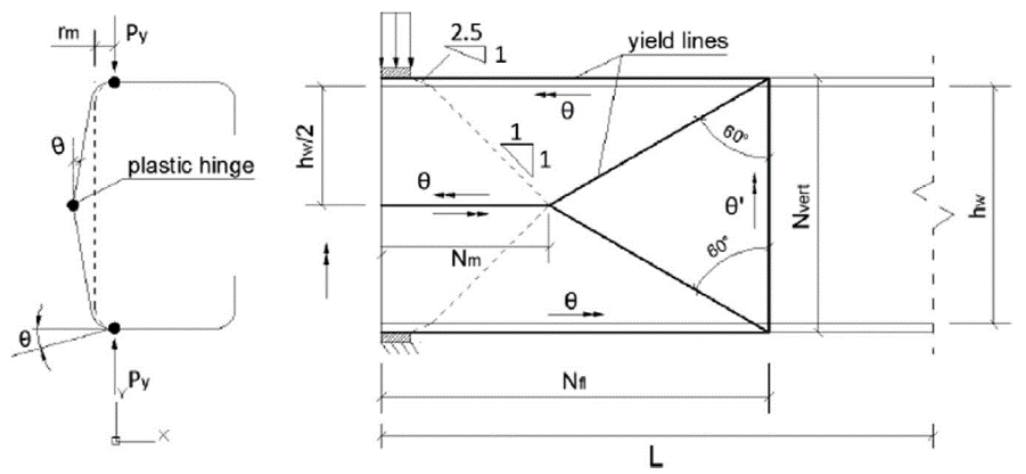

(a) Plastic mechanism - fastened ETF loading condition [39]

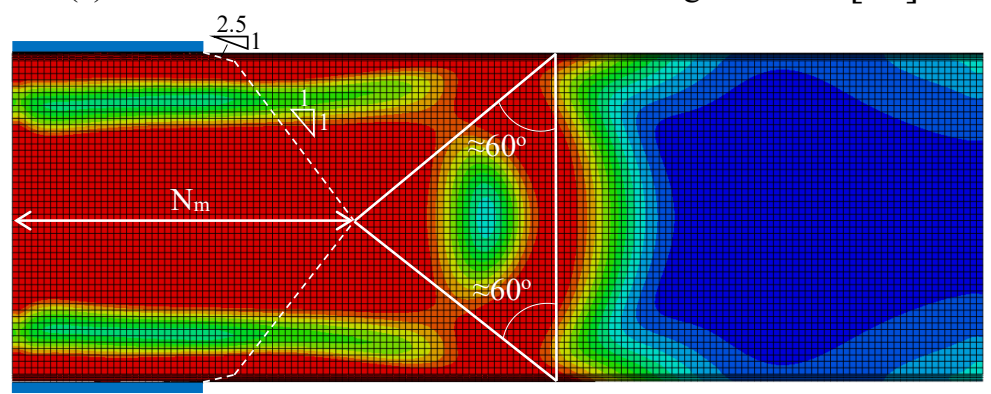

(b) von-Mises stress distributions - fastened ETF loading condition

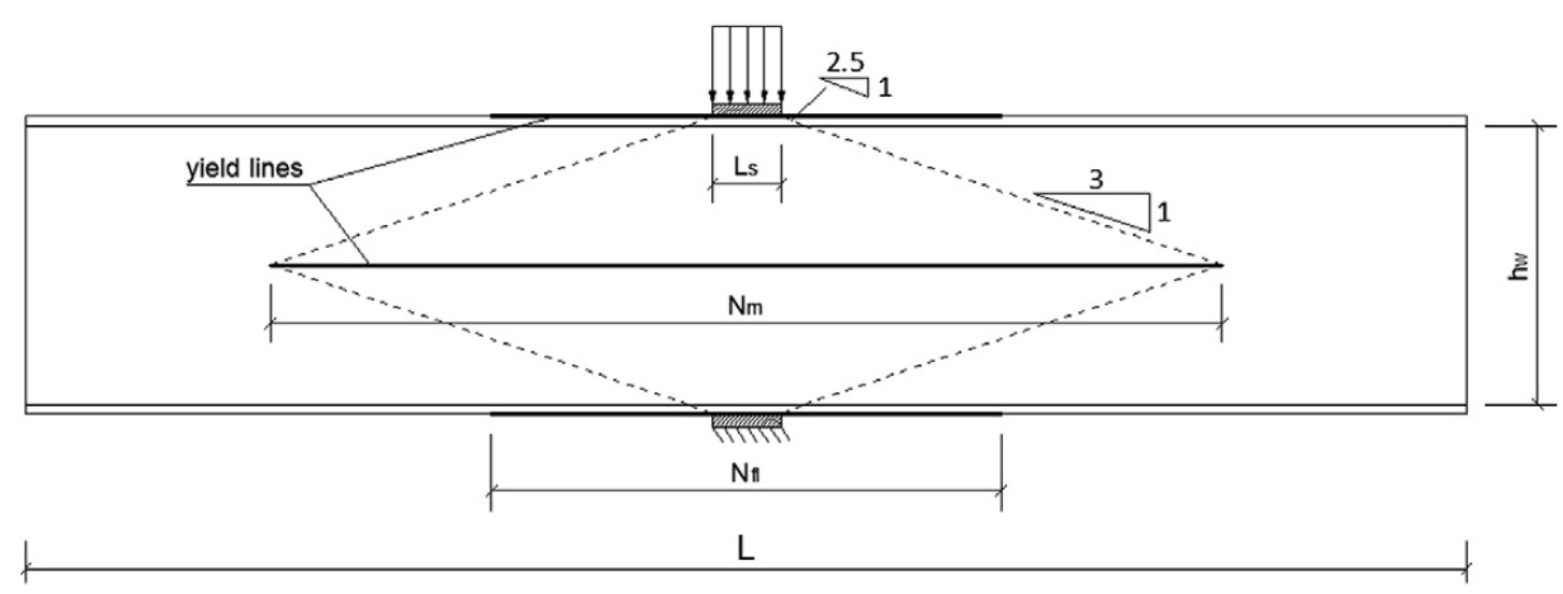

(c) Plastic mechanism - fastened ITF loading condition [40]

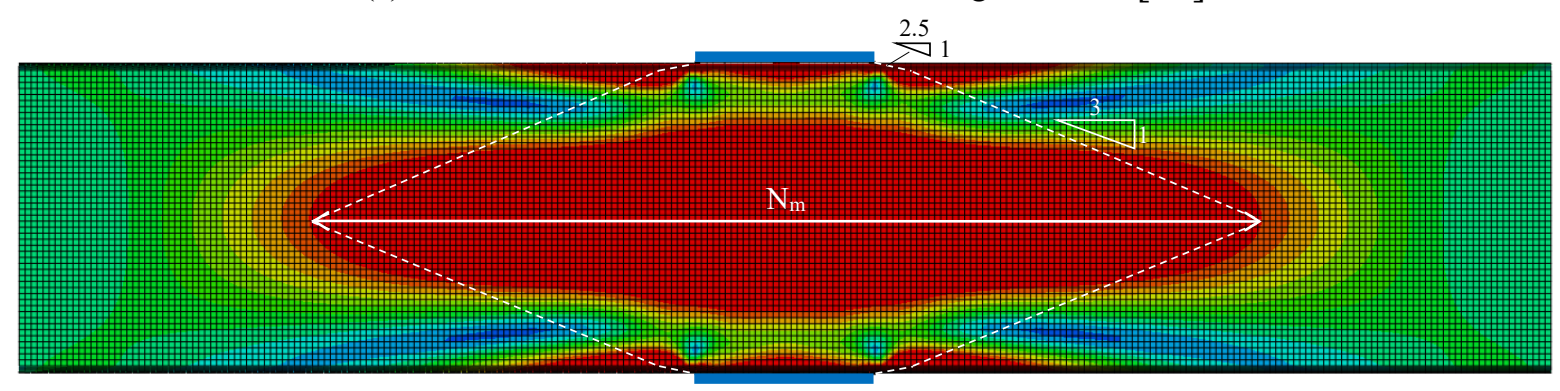

(d) von-Mises stress distributions - fastened ITF loading condition

Figure 15: Plastic mechanism proposed by Natário et al. [39, 40] and von-Mises stress distributions at the ultimate load 


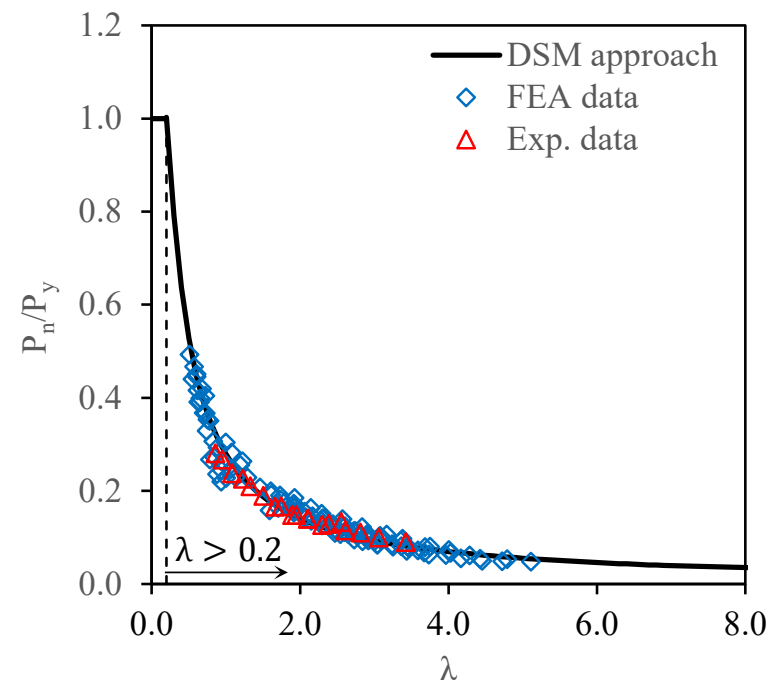

(a) ETF loading condition

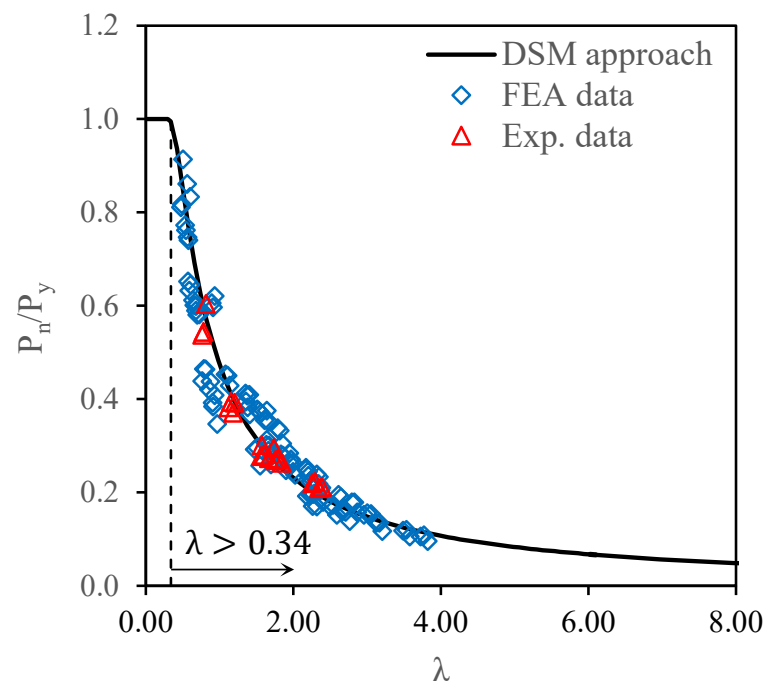

(b) ITF loading condition

Figure 16: Comparison between the web crippling strength using proposed DSM-based approach and FEAexperimental data 
Table 1: Comparison of experimental and FEA web crippling capacities for ETF loading condition

\begin{tabular}{|l|c|c|c|c|c|c|c|c|c|}
\hline Specimen & $\begin{array}{c}d \\
(\mathrm{~mm})\end{array}$ & $\begin{array}{c}b_{f} \\
(\mathrm{~mm})\end{array}$ & $\begin{array}{c}l_{b} \\
(\mathrm{~mm})\end{array}$ & $\begin{array}{c}t \\
(\mathrm{~mm})\end{array}$ & $\begin{array}{c}r_{i} \\
(\mathrm{~mm})\end{array}$ & $\begin{array}{c}L \\
(\mathrm{~mm})\end{array}$ & $\begin{array}{c}P_{\text {Exp. }} \\
(\mathrm{kN})\end{array}$ & $\begin{array}{c}P_{\text {FEA }} \\
(\mathrm{kN})\end{array}$ & $\begin{array}{c}P_{\text {Exp. }} / P_{\text {FEA }} \\
(\mathrm{kN})\end{array}$ \\
\hline ETF-10030-N25 & 107.2 & 60.5 & 14.8 & 2.95 & 4.9 & 107.2 & 6.80 & 7.13 & 0.95 \\
\hline ETF-10030-N50 & 106.4 & 58.3 & 16.2 & 2.95 & 5.0 & 106.4 & 8.44 & 8.59 & 0.98 \\
\hline ETF-10030-N100 & 107.2 & 59.3 & 15.1 & 2.95 & 4.8 & 316 & 11.25 & 12.68 & 0.89 \\
\hline ETF-15030-N25 & 156.8 & 62.9 & 23.0 & 2.93 & 4.9 & 466 & 6.37 & 7.05 & 0.90 \\
\hline ETF-15030-N50 & 157.6 & 63.2 & 22.3 & 2.93 & 5.0 & 465 & 7.84 & 7.91 & 0.99 \\
\hline ETF-15030-N100 & 158.4 & 63.3 & 21.8 & 2.92 & 5.1 & 465 & 9.92 & 10.03 & 0.99 \\
\hline ETF-15030-N150 & 155.4 & 63.4 & 23.0 & 2.92 & 4.9 & 467 & 12.45 & 13.45 & 0.93 \\
\hline ETF-20025-N25 & 208.2 & 74.5 & 25.4 & 2.42 & 5.1 & 617 & 4.74 & 5.01 & 0.95 \\
\hline ETF-20025-N50 & 208.0 & 74.3 & 25.3 & 2.43 & 4.9 & 615 & 5.15 & 5.52 & 0.93 \\
\hline ETF-20025-N100 & 207.2 & 74.2 & 25.8 & 2.43 & 5.0 & 615 & 6.19 & 6.57 & 0.94 \\
\hline ETF-20025-N150 & 204.1 & 75.9 & 26.4 & 2.43 & 4.8 & 615 & 7.51 & 8.17 & 0.92 \\
\hline ETF-20030-N25 & 204.5 & 74.9 & 27.5 & 2.9 & 4.6 & 611 & 6.45 & 7.07 & 0.91 \\
\hline ETF-20030-N50 & 208.3 & 73.1 & 27.6 & 2.9 & 5.0 & 615 & 7.37 & 7.60 & 0.97 \\
\hline ETF-20030-N100 & 204.4 & 75.5 & 27.6 & 2.89 & 4.6 & 613 & 8.64 & 9.41 & 0.92 \\
\hline ETF-20030-N150 & 208.2 & 73.4 & 27.2 & 2.89 & 5.0 & 615 & 11.05 & 11.31 & 0.98 \\
\hline ETF-25025-N25 & 259.9 & 80.7 & 23.5 & 2.43 & 4.4 & 765 & 4.45 & 4.60 & 0.97 \\
\hline ETF-25025-N50 & 259.8 & 76.2 & 23.8 & 2.44 & 4.9 & 765 & 4.90 & 4.89 & 1.00 \\
\hline ETF-25025-N100 & 262.2 & 76.1 & 22.6 & 2.44 & 4.8 & 765 & 6.20 & 5.76 & 1.08 \\
\hline ETF-25025-N150 & 260.4 & 76.2 & 23.5 & 2.45 & 4.6 & 765 & 7.20 & 6.91 & 1.04 \\
\hline & \multicolumn{7}{|c|}{ Mean } \\
\hline
\end{tabular}

Table 2: Comparison of experimental and FEA web crippling capacities for ITF loading condition

\begin{tabular}{|l|c|c|c|c|c|c|c|c|c|}
\hline Specimen & $\begin{array}{c}d \\
(\mathrm{~mm})\end{array}$ & $\begin{array}{c}b_{f} \\
(\mathrm{~mm})\end{array}$ & $\begin{array}{c}l_{b} \\
(\mathrm{~mm})\end{array}$ & $\begin{array}{c}t \\
(\mathrm{~mm})\end{array}$ & $\begin{array}{c}r_{i} \\
(\mathrm{~mm})\end{array}$ & $\begin{array}{c}L \\
(\mathrm{~mm})\end{array}$ & $\begin{array}{c}P_{\text {Exp. }} \\
(\mathrm{kN})\end{array}$ & $\begin{array}{c}P_{\text {FEA }} \\
(\mathrm{kN})\end{array}$ & $\begin{array}{c}P_{\text {Exp. }} / P_{\text {FEA }} \\
(\mathrm{kN})\end{array}$ \\
\hline ITF-10030-N25 & 106.8 & 59.3 & 14.3 & 2.94 & 4.8 & 527 & 21.88 & 21.16 & 1.03 \\
\hline ITF-10030-N50 & 106.5 & 59.4 & 14.8 & 2.95 & 4.9 & 525 & 20.79 & 19.46 & 1.07 \\
\hline ITF-10030-N100 & 106.2 & 59.6 & 14.4 & 2.94 & 4.8 & 523.5 & 23.68 & 22.85 & 1.04 \\
\hline ITF-15030-N25 & 156.6 & 62.6 & 22.6 & 2.93 & 4.8 & 774 & 19.99 & 20.40 & 0.98 \\
\hline ITF-15030-N50 & 156.8 & 62.4 & 22.7 & 2.92 & 4.9 & 775 & 19.34 & 19.59 & 0.99 \\
\hline ITF-15030-N100 & 156.3 & 62.1 & 22.7 & 2.92 & 4.8 & 776 & 22.99 & 23.61 & 0.97 \\
\hline ITF-15030-N150 & 156.7 & 62.5 & 22.8 & 2.93 & 4.9 & 774 & 23.99 & 25.98 & 0.92 \\
\hline ITF-20025-N25 & 206.3 & 74.0 & 26.3 & 2.43 & 4.6 & 1028 & 13.41 & 14.21 & 0.94 \\
\hline ITF-20025-N50 & 207.3 & 73.3 & 26.0 & 2.44 & 4.9 & 1022 & 13.93 & 14.00 & 1.00 \\
\hline ITF-20025-N100 & 207.4 & 73.9 & 26.3 & 2.43 & 5.0 & 1019 & 15.83 & 17.28 & 0.92 \\
\hline ITF-20025-N150 & 207.5 & 73.4 & 26.9 & 2.44 & 4.6 & 1021 & 16.52 & 18.70 & 0.88 \\
\hline ITF-20030-N25 & 205.5 & 74.5 & 31.6 & 2.9 & 4.4 & 1022 & 19.46 & 19.55 & 1.00 \\
\hline ITF-20030-N50 & 206.7 & 75.3 & 27.4 & 2.93 & 4.8 & 102 & 19.97 & 19.52 & 1.02 \\
\hline ITF-20030-N100 & 206.4 & 74.4 & 26.7 & 2.9 & 4.8 & 1021 & 22.63 & 23.33 & 0.97 \\
\hline ITF-20030-N150 & 206.6 & 74.5 & 26.7 & 2.89 & 4.6 & 1022 & 22.67 & 24.68 & 0.92 \\
\hline ITF-25025-N25 & 259.8 & 76.1 & 22.1 & 2.43 & 4.4 & 1273 & 14.21 & 13.38 & 1.06 \\
\hline ITF-25025-N50 & 260.1 & 76.0 & 22.4 & 2.42 & 4.5 & 1274 & 14.05 & 13.99 & 1.00 \\
\hline ITF-25025-N100 & 259.9 & 76.3 & 22.5 & 2.43 & 4.5 & 1269 & 15.99 & 15.99 & 1.00 \\
\hline ITF-25025-N150 & 259.8 & 76.2 & 22.2 & 2.43 & 4.5 & 1275 & 16.72 & 16.40 & 1.02 \\
\hline & \multicolumn{7}{|c|}{ Mean } \\
\hline
\end{tabular}


Table 3. Mechanical properties of aluminium sections used in the numerical simulations [30]

\begin{tabular}{|c|c|c|c|c|c|c|c|}
\hline Section & $\begin{array}{c}E \\
(\mathrm{GPa})\end{array}$ & $\begin{array}{c}\sigma_{0.2 \text {,Eng }} \\
(\mathrm{MPa})\end{array}$ & $\begin{array}{c}\sigma_{0.2, \text { true }} \\
(\mathrm{MPa})\end{array}$ & $\begin{array}{c}\sigma_{u, \text { Eng. }} \\
(\mathrm{MPa})\end{array}$ & $\begin{array}{c}\sigma_{u, \text { True }} \\
(\mathrm{MPa})\end{array}$ & $\begin{array}{c}\varepsilon_{u, \text { Eng. }} \\
(\%)\end{array}$ & $\begin{array}{c}\varepsilon_{u, \text { True }} \\
(\%)\end{array}$ \\
\hline 10030 & 65.05 & 210 & 223 & 259 & 274.93 & 6.15 & 5.97 \\
\hline 15030 & 63.55 & 206 & 217 & 248 & 261.76 & 5.55 & 5.40 \\
\hline 20025 & 63.95 & 214 & 225 & 260 & 273.13 & 5.05 & 4.93 \\
\hline 20030 & 64.13 & 212 & 226 & 257 & 273.63 & 6.47 & 6.27 \\
\hline 25025 & 64.34 & 216 & 230 & 265 & 282.70 & 6.68 & 6.47 \\
\hline
\end{tabular}

Table 4: Parametric study model details of ALC sections under ETF and ITF loading conditions

\begin{tabular}{|c|c|c|c|c|c|c|}
\hline $\begin{array}{l}\text { Loading } \\
\text { condition }\end{array}$ & Section & $\begin{array}{c}N \\
(\mathrm{~mm})\end{array}$ & $h / t$ & $\begin{array}{c}r_{i} \\
(\mathrm{~mm})\end{array}$ & $\begin{array}{l}\text { Aluminium } \\
\text { hardening }\end{array}$ & $\begin{array}{l}\text { Number } \\
\text { of } \\
\text { models }\end{array}$ \\
\hline \multirow[t]{9}{*}{ ETF } & 10030 & $50,100,150$ & $27.7-31.7$ & $2,5,8$ & $\begin{array}{c}\mathrm{H} 32, \mathrm{H} 36, \\
\text { H38 }\end{array}$ & 27 \\
\hline & 15025 & $50,100,150$ & $53.6-58.4$ & $2,5,8$ & H36 & 9 \\
\hline & 25025 & $50,100,150$ & $96-98.4$ & $2,5,8$ & $\begin{array}{c}\text { H32, H36, } \\
\text { H38 }\end{array}$ & 27 \\
\hline & 25030 & $50,100,150$ & $77.7-81.7$ & $2,5,8$ & $\mathrm{H} 36$ & 9 \\
\hline & 30025 & $50,100,150$ & $\begin{array}{l}110.6- \\
116.4\end{array}$ & $2,5,8$ & H36 & 9 \\
\hline & 40030 & $50,100,150$ & $126-130$ & $2,5,8$ & $\begin{array}{c}\text { H32, H36, } \\
\text { H38 }\end{array}$ & 27 \\
\hline & \multicolumn{5}{|c|}{ Experiment } & 19 \\
\hline & \multicolumn{5}{|c|}{ FE-validation } & 19 \\
\hline & \multicolumn{5}{|c|}{ Sub-total } & 146 \\
\hline \multirow[t]{9}{*}{ ITF } & 10030 & $50,100,150$ & $27.7-31.7$ & $2,5,8$ & $\begin{array}{c}\text { H32, H36, } \\
\text { H38 }\end{array}$ & 27 \\
\hline & 15025 & $50,100,150$ & $53.6-58.4$ & $2,5,8$ & H36 & 9 \\
\hline & 25025 & $50,100,150$ & $96-98.4$ & $2,5,8$ & $\begin{array}{c}\mathrm{H} 32, \mathrm{H} 36, \\
\text { H38 }\end{array}$ & 27 \\
\hline & 25030 & $50,100,150$ & $77.7-81.7$ & $2,5,8$ & H36 & 9 \\
\hline & 30025 & $50,100,150$ & $\begin{array}{c}110.6- \\
116.4\end{array}$ & $2,5,8$ & H36 & 9 \\
\hline & 40030 & $50,100,150$ & $126-130$ & $2,5,8$ & $\begin{array}{c}\text { H32, H36, } \\
\text { H38 }\end{array}$ & 27 \\
\hline & Experiment & & & & & 19 \\
\hline & $\begin{array}{l}\text { FE- } \\
\text { validation }\end{array}$ & & & & & 19 \\
\hline & Sub-total & & & & & 146 \\
\hline & & & & & & 292 \\
\hline
\end{tabular}

Note: $\quad \mathrm{H} 32$ : (yield stress $\left(f_{y}\right)=145 \mathrm{MPa}$, ultimate stress $\left(f_{u}\right)=214 \mathrm{MPa}$ and Young's Modulus $\left.(E)=70 \mathrm{GPa}\right)$ H36 : $\left(f_{y}=179 \mathrm{MPa}, f_{u}=255 \mathrm{MPa}\right.$ and $\left.E=69.3 \mathrm{GPa}\right)$

H38 : $\left(f_{y}=207 \mathrm{MPa}, f_{u}=268 \mathrm{MPa}\right.$ and $\left.E=70.3 \mathrm{GPa}\right)$

Table 5: Geometrical coefficients used in Equations (6) and (11)

\begin{tabular}{|c|c|c|c|c|c|}
\hline Design rule & $\begin{array}{c}\text { Loading } \\
\text { condition }\end{array}$ & $C$ & $C_{R}$ & $C_{N}$ & $C_{h}$ \\
\hline \multirow{2}{*}{ AS/NZS 4600 [32] } & ETF & 7.50 & 0.08 & 0.12 & 0.048 \\
\cline { 2 - 6 } & ITF & 20.00 & 0.10 & 0.08 & 0.031 \\
\hline Modified [28] & ETF & 0.273 & 0.21 & 0.16 & 0.06 \\
\cline { 2 - 7 } & ITF & 0.78 & 0.17 & 0.04 & 0.03 \\
\hline
\end{tabular}


Table 6: Comparison of mean and COV values for ultimate-to-predicted web crippling capacity ratios $\left(P_{\text {Exp.FEA }} / P_{\text {Predicted }}\right)$

\begin{tabular}{|c|c|c|c|c|c|c|}
\hline Rule & $\begin{array}{l}\text { Loading } \\
\text { condition }\end{array}$ & Equation & Mean & $\mathrm{COV}$ & $\phi_{w}$ & $\beta_{0}$ \\
\hline \multirow[t]{6}{*}{ Current } & \multirow[t]{3}{*}{ ETF } & $\begin{array}{l}\text { AS/NZS } 1664.1 \\
{[31]}\end{array}$ & 0.68 & 0.26 & 0.90 & 0.64 \\
\hline & & AS/NZS 4600 [32] & 0.55 & 0.13 & 0.85 & 0.25 \\
\hline & & Eurocode 3 [33] & 0.86 & 0.13 & 1.00 & 1.30 \\
\hline & \multirow[t]{3}{*}{ ITF } & $\begin{array}{l}\text { AS/NZS } 1664.1 \\
{[31]}\end{array}$ & 1.04 & 0.13 & 0.90 & 2.48 \\
\hline & & AS/NZS 4600 [32] & 0.65 & 0.11 & 0.85 & 0.91 \\
\hline & & Eurocode 3 [33] & 0.87 & 0.17 & 1.00 & 1.29 \\
\hline \multirow[t]{6}{*}{ Modified } & \multirow[t]{3}{*}{ ETF } & Equation (9) & 1.06 & 0.11 & 0.90 & 2.67 \\
\hline & & Equation (11) & 1.04 & 0.08 & 0.90 & 2.69 \\
\hline & & Equation (12) & 0.99 & 0.13 & 0.85 & 2.50 \\
\hline & \multirow[t]{3}{*}{ ITF } & Equation (10) & 1.10 & 0.09 & 0.90 & 2.89 \\
\hline & & Equation (11) & 1.03 & 0.06 & 0.90 & 2.72 \\
\hline & & Equation (13) & 1.04 & 0.10 & 0.90 & 2.65 \\
\hline \multirow[t]{2}{*}{ Proposed } & ETF & DSM approach & 1.01 & 0.11 & 0.85 & 2.70 \\
\hline & ITF & DSM approach & 1.01 & 0.13 & 0.85 & 2.58 \\
\hline
\end{tabular}

Table 7: Comparison of FEA and proposed critical buckling loads - ETF loading condition

\begin{tabular}{|l|c|c|c|c|c|c|}
\hline Specimen & $\begin{array}{c}r_{i} \\
(\mathrm{~mm})\end{array}$ & $\begin{array}{c}P_{\text {cr(FEM })} \\
(\mathrm{kN})\end{array}$ & $k_{\text {cr(FEA) }}$ & $k_{\text {cr(Prop. })}$ & $\begin{array}{c}P_{\text {cr(Prop. })} \\
(\mathrm{kN})\end{array}$ & $\begin{array}{c}P_{\text {cr(FEM })} / \\
P_{\text {cr(Prop. })}\end{array}$ \\
\hline ETF-10030-N50 & 5.00 & 39.60 & 2.41 & 2.43 & 39.98 & 0.99 \\
\hline ETF-10030-N50 & 8.00 & 39.90 & 2.42 & 2.43 & 39.98 & 1.00 \\
\hline ETF-10030-N100 & 5.00 & 66.80 & 4.06 & 3.86 & 63.49 & 1.05 \\
\hline ETF-10030-N100 & 8.00 & 65.00 & 3.95 & 3.86 & 63.49 & 1.02 \\
\hline ETF-10030-N150 & 5.00 & 94.20 & 5.72 & 5.29 & 87.01 & 1.08 \\
\hline ETF-10030-N150 & 8.00 & 87.30 & 5.30 & 5.29 & 87.01 & 1.00 \\
\hline ETF-25025-N50 & 5.00 & 6.10 & 1.56 & 1.59 & 6.23 & 0.98 \\
\hline ETF-25025-N50 & 8.00 & 6.10 & 1.56 & 1.59 & 6.23 & 0.98 \\
\hline ETF-25025-N100 & 5.00 & 8.44 & 2.15 & 2.18 & 8.54 & 0.99 \\
\hline ETF-25025-N100 & 8.00 & 8.30 & 2.12 & 2.18 & 8.54 & 0.97 \\
\hline ETF-25025-N150 & 5.00 & 11.10 & 2.83 & 2.76 & 10.84 & 1.02 \\
\hline ETF-25025-N150 & 8.00 & 10.90 & 2.78 & 2.76 & 10.84 & 1.01 \\
\hline ETF-40030-N50 & 5.00 & 6.00 & 1.39 & 1.38 & 5.94 & 1.01 \\
\hline ETF-40030-N50 & 8.00 & 5.96 & 1.38 & 1.38 & 5.94 & 1.00 \\
\hline ETF-40030-N100 & 5.00 & 7.47 & 1.73 & 1.75 & 7.56 & 0.99 \\
\hline ETF-40030-N100 & 8.00 & 7.37 & 1.71 & 1.75 & 7.56 & 0.97 \\
\hline ETF-40030-N150 & 5.00 & 9.14 & 2.12 & 2.13 & 9.18 & 1.00 \\
\hline ETF-40030-N150 & 8.00 & 8.99 & 2.08 & 2.13 & 9.18 & 0.98 \\
\hline & \multicolumn{7}{|l|}{ Mean } & & 1.00 \\
\hline
\end{tabular}


Table 8: Comparison of FEA and proposed critical buckling loads - ITF loading condition

\begin{tabular}{|c|c|c|c|c|c|c|}
\hline Specimen & $\begin{array}{c}r_{i} \\
(\mathrm{~mm})\end{array}$ & $\begin{array}{c}P_{c r(F E M)} \\
(\mathrm{kN})\end{array}$ & $k_{c r(F E A)}$ & $k_{c r \text { (Prop.) }}$ & $\begin{array}{c}P_{c r \text { (Prop.) }} \\
(\mathrm{kN})\end{array}$ & $\begin{array}{l}P_{c r \text { (FEM) }} / \\
P_{c r \text { (Prop. }}\end{array}$ \\
\hline ITF-10030-N50 & 5.00 & 68.40 & 4.16 & 4.35 & 71.64 & 0.95 \\
\hline ITF-10030-N50 & 8.00 & 69.60 & 4.23 & 4.35 & 71.64 & 0.97 \\
\hline ITF-10030-N100 & 5.00 & 86.10 & 5.23 & 5.30 & 87.32 & 0.99 \\
\hline ITF-10030-N100 & 8.00 & 85.50 & 5.19 & 5.30 & 87.32 & 0.98 \\
\hline ITF-10030-N150 & 5.00 & 108.30 & 6.58 & 6.26 & 103.00 & 1.05 \\
\hline ITF-10030-N150 & 8.00 & 105.60 & 6.42 & 6.26 & 103.00 & 1.03 \\
\hline ITF-25025-N50 & 5.00 & 14.90 & 3.80 & 3.79 & 14.87 & 1.00 \\
\hline ITF-25025-N50 & 8.00 & 15.10 & 3.85 & 3.79 & 14.87 & 1.02 \\
\hline ITF-25025-N100 & 5.00 & 16.20 & 4.13 & 4.18 & 16.41 & 0.99 \\
\hline ITF-25025-N100 & 8.00 & 16.30 & 4.16 & 4.18 & 16.41 & 0.99 \\
\hline ITF-25025-N150 & 5.00 & 17.70 & 4.51 & 4.58 & 17.95 & 0.99 \\
\hline ITF-25025-N150 & 8.00 & 17.80 & 4.54 & 4.58 & 17.95 & 0.99 \\
\hline ITF-40030-N50 & 5.00 & 15.80 & 3.66 & 3.65 & 15.77 & 1.00 \\
\hline ITF-40030-N50 & 8.00 & 15.90 & 3.68 & 3.65 & 15.77 & 1.01 \\
\hline ITF-40030-N100 & 5.00 & 16.70 & 3.86 & 3.90 & 16.85 & 0.99 \\
\hline ITF-40030-N100 & 8.00 & 16.78 & 3.88 & 3.90 & 16.85 & 1.00 \\
\hline ITF-40030-N150 & 5.00 & 17.70 & 4.10 & 4.15 & 17.93 & 0.99 \\
\hline ITF-40030-N150 & 8.00 & 17.70 & 4.10 & 4.15 & 17.93 & 0.99 \\
\hline \multicolumn{6}{|c|}{ Mean } & 1.00 \\
\hline \multicolumn{6}{|c|}{$\mathrm{COV}$} & 0.02 \\
\hline
\end{tabular}

